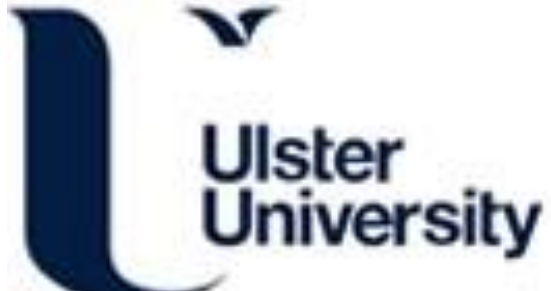

\section{Experimental study on flame morphologic characteristics of wall attached non- premixed buoyancy driven turbulent flames}

Zhang, X., Hu, L., Delichatsios, M., \& Zhang, J. (2019). Experimental study on flame morphologic characteristics of wall attached non-premixed buoyancy driven turbulent flames. Applied Energy, 254, 1-13. [113672]. https://doi.org/10.1016/j.apenergy.2019.113672

Link to publication record in Ulster University Research Portal

\section{Published in:}

Applied Energy

Publication Status:

Published (in print/issue): 15/11/2019

DOI:

10.1016/j.apenergy.2019.113672

\section{Document Version}

Author Accepted version

\section{General rights}

Copyright for the publications made accessible via Ulster University's Research Portal is retained by the author(s) and / or other copyright owners and it is a condition of accessing these publications that users recognise and abide by the legal requirements associated with these rights.

\section{Take down policy}

The Research Portal is Ulster University's institutional repository that provides access to Ulster's research outputs. Every effort has been made to ensure that content in the Research Portal does not infringe any person's rights, or applicable UK laws. If you discover content in the Research Portal that you believe breaches copyright or violates any law, please contact pure-support@ulster.ac.uk. 


\title{
Experimental study on flame morphologic characteristics of wall attached non-premixed buoyancy driven turbulent flames
}

\author{
Xiaolei Zhanga, Longhua $\mathrm{Hu}^{\mathrm{a} *}$, Michael A. Delichatsios ${ }^{\mathrm{a}, \mathrm{b}}$, Jianping Zhang ${ }^{\mathrm{c}}$ \\ ${ }^{a}$ State Key Laboratory of Fire Science, \\ University of Science and Technology of China, \\ Hefei, Anhui, 230026, China \\ ${ }^{\mathrm{b}}$ Department of Mechanical and Industrial Engineering, \\ Northeastern University, Boston, USA \\ ${ }^{c}$ FireSERT, School of Built Environment, \\ Ulster University, Newtownabbey, BT37 0QB, Northern Ireland, UK
}

*Corresponding author: Tel: (86) 551 63606446; Fax: (86) 551 63601669; Email address: hlh@ustc.edu.cn; Postal address: State Key Laboratory of Fire Science, University of Science and Technology of China, Hefei, Anhui, 230026, China. 


\section{Abstract}

This work investigates the effects of the wall on the morphologic characteristics of non-premixed buoyancy driven turbulent flames attached to the wall. Experiments are carried out with rectangular burners having their long side attached to a wall. The investigation is based on dimensional analysis and comprehensive experimental data, including comparison of the flame characteristics of the wall attached flames with free flames. Results show that the non-dimensional flame heights of wall attached flames experience a two-dimensional to three-dimensional transition as free flames do. The critical dimensionless heat release rate for this transition is smaller for the wall attached flames $(0.30)$ than that of the free flames (0.39). The flame height fluctuation of wall attached flames is smaller than that of free flames and decreases with an increase in the nozzle aspect ratio. The ratio of flame thickness (or flame width) to flame height of wall attached flames is smaller than that of free flames. New correlations for flame height, width and thickness of the wall attached flames are proposed based on the mirror-approach of the rectangular source relative to that of a free flame, where the burner perimeter is found to be an appropriate length scale. This work provides important knowledge on the effect of wall on flame characteristics of buoyancy driven buoyant turbulent flames, which is essential to the design and risk assessment of the laying of gaseous fuel transportation pipelines in the city and also provides data for validation of computational fluid dynamics (CFD) models.

Key words: Wall attached buoyancy driven turbulent flames; flame height; flame fluctuation; flame thickness; flame width; heat release rate. 


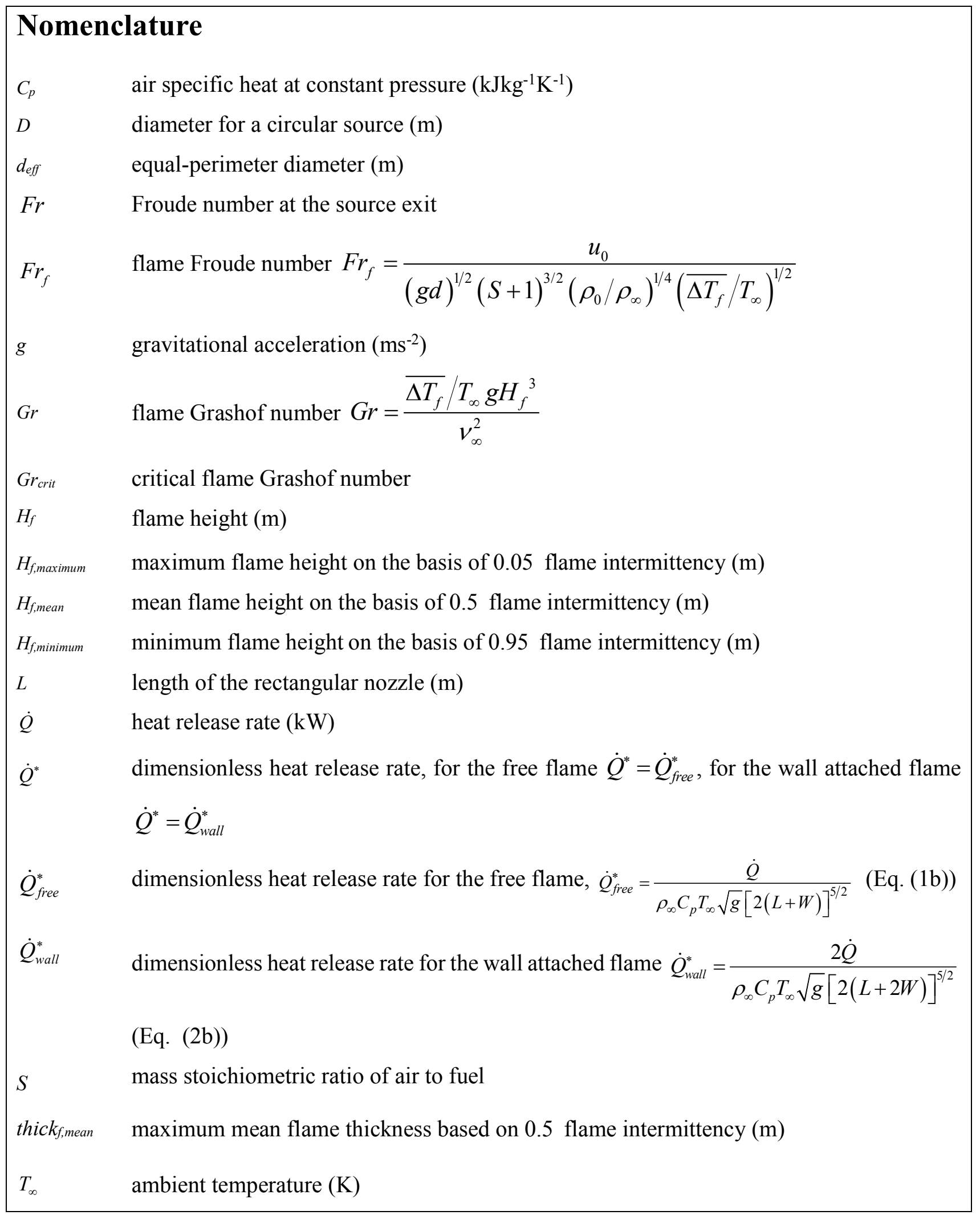




\begin{tabular}{|ll|}
\hline$u_{0}$ & gaseous fuel flow velocity $\left(\mathrm{ms}^{-1}\right)$ \\
$W$ & width of rectangular fuel source $(\mathrm{m})$ \\
$W_{f, \text { mean }}$ & maximum mean flame width based on 0.5 flame intermittency $(\mathrm{m})$ \\
Greek symbols \\
$\rho_{0}$ & fuel density at the environment condition $\left(\mathrm{kgm}^{-3}\right)$ \\
$\rho_{\infty}$ & density of the ambient air $\left(\mathrm{kgm}^{-3}\right)$ \\
$\overline{\Delta T_{f}}$ & mean flame temperature rise $(\mathrm{K})$ \\
$\Delta \delta$ & mesh size (m) \\
$v_{\infty}$ & kinematic viscosity $\left(\mathrm{m}^{2} \mathrm{~s}^{-1}\right)$ \\
Subscript & \\
$\infty$ & ambient \\
$f$ & flame \\
\hline
\end{tabular}




\section{Introduction}

The report of "BP Statistical Review of World Energy" [1] showed that the natural gas consumption of China in recent 10 years has been increasing year by year with a growth rate of $15 \%$ from 2016 to 2017 as shown in Fig. 1a. The increasing demand for gas fuels has stimulated the increasing use of natural gas pipelines in cities, which while making the utilization of public energy convenient is accompanied with greater risks of the pipeline leakage [2-4]. As a consequence, studies on the flame characteristics resulted from the pipeline leakage were conducted for both the normal atmospheric pressure [2] and the reduced pressure [3], in which the flame height correlations for different atmospheric pressures were proposed.
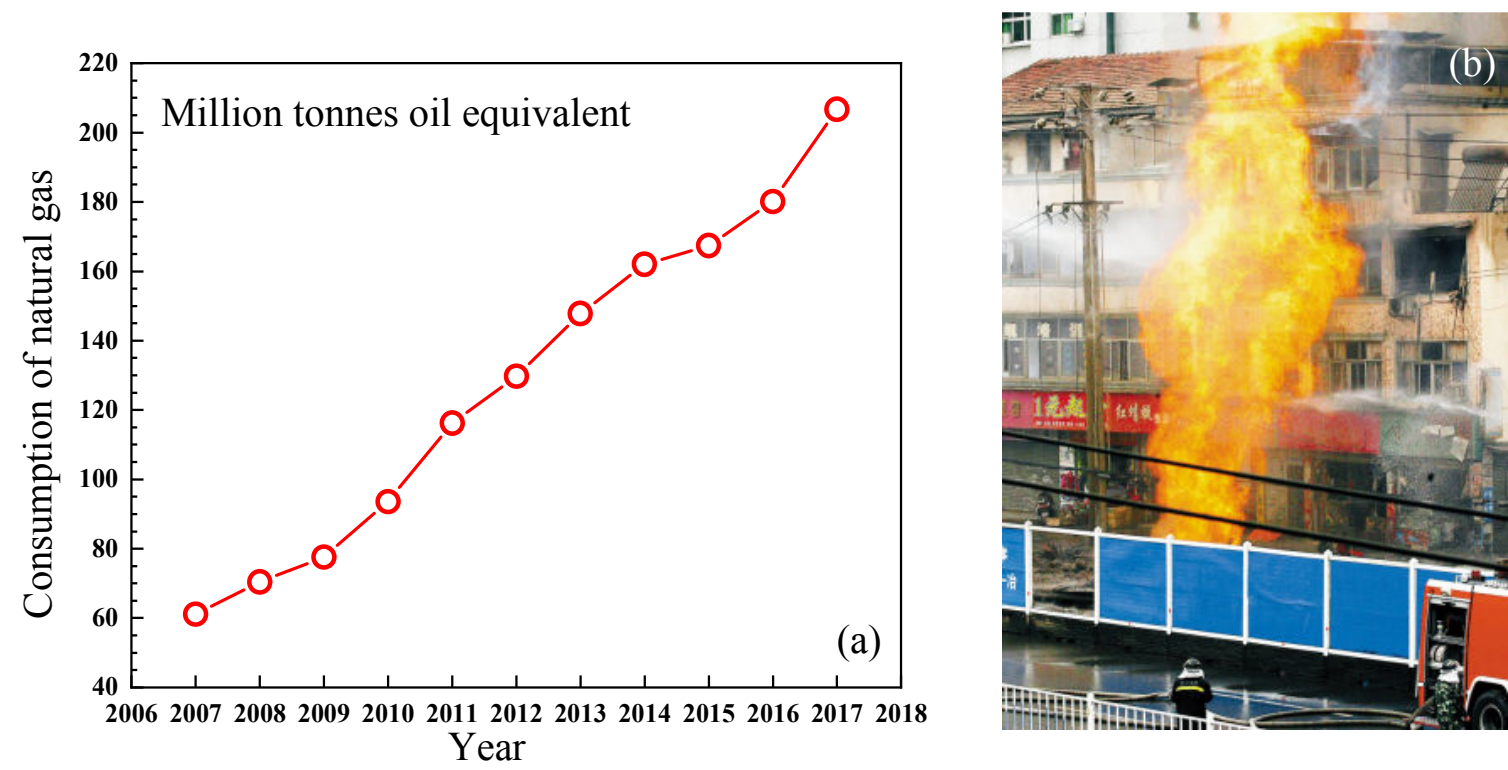

Figure 1. a) Increasing natural gas consumption of China in recent 10 years; b) A case of nature gas pipeline leakage fire accident near a building wall in the city [Cited from http://news.sina.com.cn] (consulted on 12/2018).

Since gaseous fuels have been used to provide energy in many fields, its combustion as well as flame characteristics during the energy utilization and transportation have been studied extensively [4-9]. Zhang et al. [4] proposed a mathematical model for flame volume estimation. Tang et al. [5] studied the combustion behavior of premixed propane flame with hydrogen addition in a combustor. Wierzbicki et al. 
[6] revealed the effect of $\mathrm{Pt}$ and $\mathrm{Rh}$ catalysts on the combustion of propane in a meso-scale heat recirculation combustor. Kumar et al. [7] found that the addition of nitrogen would affect the flame height, soot free length fraction, radiant fraction, gas temperature and emissions of liquefied petroleum gas (LPG) diffusion flames. Akbari et al. [8] numerically investigated the flammability limit and flame stability of porous burners. Rashwan et al. [9] made experimental investigations of partially premixed methane flames on the flammability limits, flame length, appearance and color. Additionally, extensive researches on risk issues of energy conversion and application have been conducted, since safety principles are fundamental guidelines for the utilization of the energy [4, 10-13]. Hughes et al. [10] proposed a systematic method for analyzing risk to energy systems, which could use both qualitative and quantitative data, and three worked examples illustrated the method. Su et al. [11] proposed a method to analyze reliability of supply of natural gas pipeline networks. Witkowski et al. [12] studied the safety problem of combustion product $\mathrm{CO}_{2}$ sequestration. Rimkevicius et al. [13] developed an approach for reliability assessment of district heating, gas and oil supply networks. Gaseous fuels are often stored in tank or transported in pipelines at high pressure. It has been reported that the pipeline leakage (or a broken relief valve) can produce large scale non-premixed buoyant turbulent flames resulting in serious damage to the surroundings due to its large heat fluxes as well as pollution impact to the environment, especially in cities where buildings are highly clustered $[14,15]$ (Fig. 1b). Clearly, the fire risk due to the buoyant turbulent flames is considerable and should be treated seriously in energy conversion and management.

Flame morphologic characteristics (flame height, flame width, flame thickness, etc.) of a fuel gas leakage non-premixed buoyant turbulent flames are important parameters to evaluate its risk and impact to the surroundings [16]. Previous works reported in the literatures are mainly concentrated on the flame morphologic characteristics under free condition [16-19]. Palacios et al. [16] conducted large scale experiments to study the flame shape, flame length and flame width, and comparison with previous works 
was made. Kang et al. [17] found that the flame characteristics behaved at two regimes with the increase of hydrogen mole fraction for a dimethyl ether diffusion flame with $\mathrm{H}_{2}$ addition. Shang et al. [18] studied the flame downwash length of non-premixed flames under the effect of wind. Lee et al. [19] studied the lift off behavior of jet flames with the effect of wind. We should notice that the leakage direction and pressure of gas are also important to the flame characteristics, and some works in the literatures have been reported for free conditions. The horizontal flame length and the vertical flame height of horizontally oriented turbulent flames for different heat release rates and release pressures produced by circular burners have been studied and correlated in [20-22]. Smith et al. [23] and Zhang et al. [24] studied the flame size of horizontally oriented flames produced by elliptic burners and rectangular burners, respectively. However, in the urban areas where there are dense buildings, the flame produced by pipeline leakage is affected by the building walls as shown in Fig. 1b, where a wall attached flame is present. Because of the restriction of air entrainment due to the wall, the flame characteristics of wall attached buoyant turbulent flame are expected to be different from those of free flames. So, it is necessary to investigate the flame morphologic characteristics of wall attached gaseous non-premixed buoyant turbulent flames with the effect of surrounding buildings, i.e., by a building wall [2]. This work focuses on the effects of a side wall on vertical buoyancy driven turbulent flames with different heat release rates.

Previous studies on flame morphologic characteristics of wall attached flames are still limited, and most of them are concentrated on flame heights where several different methods are used to determine flame heights [25-33]. Back et al. [25] reported some flame height data for wall attached flames using the $50 \%$ intermittency criterion and compared with the values deduced from thermocouple measurements using the $500{ }^{\circ} \mathrm{C}$ average centerline temperature criterion. Delichatsios [26] proposed a correlation for the flame height of a two-dimensional turbulent wall fire measured using the $50 \%$ intermittency criterion. Kulkarni [28] reported some data of wall attached flames which were deduced from video recordings 
frame by frame, by an average of 30 consecutive flame tip heights. Some simulations $[29,32]$ were also conducted for wall-attached flames, in which, Jangi et al. [29] defined the flame height based on the temperature criterion. In [30], the flame height was an average of three measurements, namely average luminous image fields; binary identification of flame on each instantaneous image and then, by averaging; 50\% flame intermittency criterion. Quintiere et al. [31] conducted experiments and proposed an expression of the flame height for wall flames, in which the flame height was the average value of the maximum visible luminous flame height observed from eleven continuous video records. For the rectangular source, Hasemi [27] reported the average flame tip heights which were the average of the height of flame tips observed for three minutes at intervals of 0.5 seconds on the videotape. For the square source, Hasemi et al. [33] studied the maximum flame height defined as the limit of the existence of flame tips in visual observations, and they also studied the height of continuous flames defined as the limit under which a solid flame was always observed in videotape. Meanwhile at present, little research addressed other flame characteristics (flame fluctuation, flame width, flame thickness) of wall attached flames, these factors reflect the effect of the wall on the air entrainment and mixing of the flame [34]. The presence or absence of a wall affects the air entrainment as well as the flame (height) fluctuations, both of which are important in determining the flame geometries $[34,35]$. And it is necessary to study the wall attached flame height fluctuations and compare it to that of a free flame in order to understand their differences in turbulence. In addition to flame height and fluctuations, the width (in the direction parallel to the wall) and thickness (in the direction normal to the wall) of the flame against a wall are also important for evaluating the thermal impact to the wall as well as the radiation to nearby flammable objects [25]. However, no research has been investigated on these two flame morphologic characteristics attached to a wall. Furthermore, the shape (or aspect ratio) of the fire source is expected to have an important influence on the flame behavior. In reality, the fuel source can be simplified as (i) axisymmetric (aspect ratio (burner 
length to burner width)=1), (ii) rectangular and (iii) linear (aspect ratio is very large, e.g. 100:1). Therefore, it is also necessary to study the above flame morphologic characteristics for different source aspect ratios to have general applications.

Based on above knowledge gap, the present work investigated experimentally the flame morphologic characteristics of buoyancy driven turbulent flames issuing from nozzles attached to a wall. Rectangular nozzles with various aspect ratios were employed. The flame height and fluctuations, flame width and flame thickness were quantified and correlated with the nozzle geometry and the heat release rate. The differences of flame morphologic characteristics between wall attached flames and free flames were quantified and discussed with regard to changes of air entrainment and mixing for various source aspect ratios. Correlations for the flame height, flame fluctuation, flame width and flame thickness were proposed. These observations are essential for the assessment of risk and environmental impact of gas fuel transportation leakage in the urban. And it also provides the basic knowledge about buoyancy driven turbulent flames attached to a wall, which is related to the design of gaseous fuel storage and transportation systems in the urban area.

\section{Experiments}

Figure $2 \mathrm{a}$ depicts the experimental setup, instrumentation as well as the definition of flame morphologic characteristics for the wall-attached flames. Four rectangular propane nozzles as designed in detail in [36] were employed with exit dimensions $W$ (width, normal to wall) $\times L$ (length, parallel to wall) of $2 \mathrm{~mm} \times 142.5 \mathrm{~mm}, 4 \mathrm{~mm} \times 71.25 \mathrm{~mm}, 5.97 \mathrm{~mm} \times 47.75 \mathrm{~mm}, 16.88 \mathrm{~mm} \times 16.88 \mathrm{~mm}$ having aspect ratio varying from $71: 1$ to $1: 1$. These shapes were used to represent the source aspect ratios in reality which vary from 1 to very large values. Propane was used in this work because it is more easily available than methane due to its lower cost and had been used widely in the previous studies on gaseous diffusion flame combustion $[2-5,16,18]$. The flame heights of different fuels including both propane and methane 
were compared in [28] and it was found that there is nearly no difference between propane and methane. The controlling factor on the flame height is the heat release rate. So, Propane was used as the fuel in this work. Propane fuel flows through a pressure gauge, a flow meter and then through a plenum chamber into the rectangular burner source. The wall was made of a mica board (thickness of $0.02 \mathrm{~m}$, size of $2.5 \mathrm{~m}$ (height) $\times 1.25 \mathrm{~m}$ (width)) having low thermal conductivity and good heat resistance. The fuel supply rates were monitored and controlled by a flow rate meter. The heat release rates $(H R R)$ ranged from 2.23$19.64 \mathrm{~kW}$ for the wall attached buoyancy driven turbulent $\mathrm{t}$ flames so the flame height was less than that of the wall (the Froude number at the source $F r=u_{0} /\left(g d_{\text {eff }}\right)^{0.5}$ ranged from $\left.0.101-1.834\right)$ where $u_{0}$ was the flow velocity of the fuel at the exit of the nozzle, $g$ was the acceleration of gravity, and $d_{\text {eff }}$ was the equalperimeter diameter of the nozzle. For the free flames, the HRR ranged from 11.29-36.13 kW (with larger heat release rates than those of the wall attached flames) (Fr ranged from 0.494-2.657).

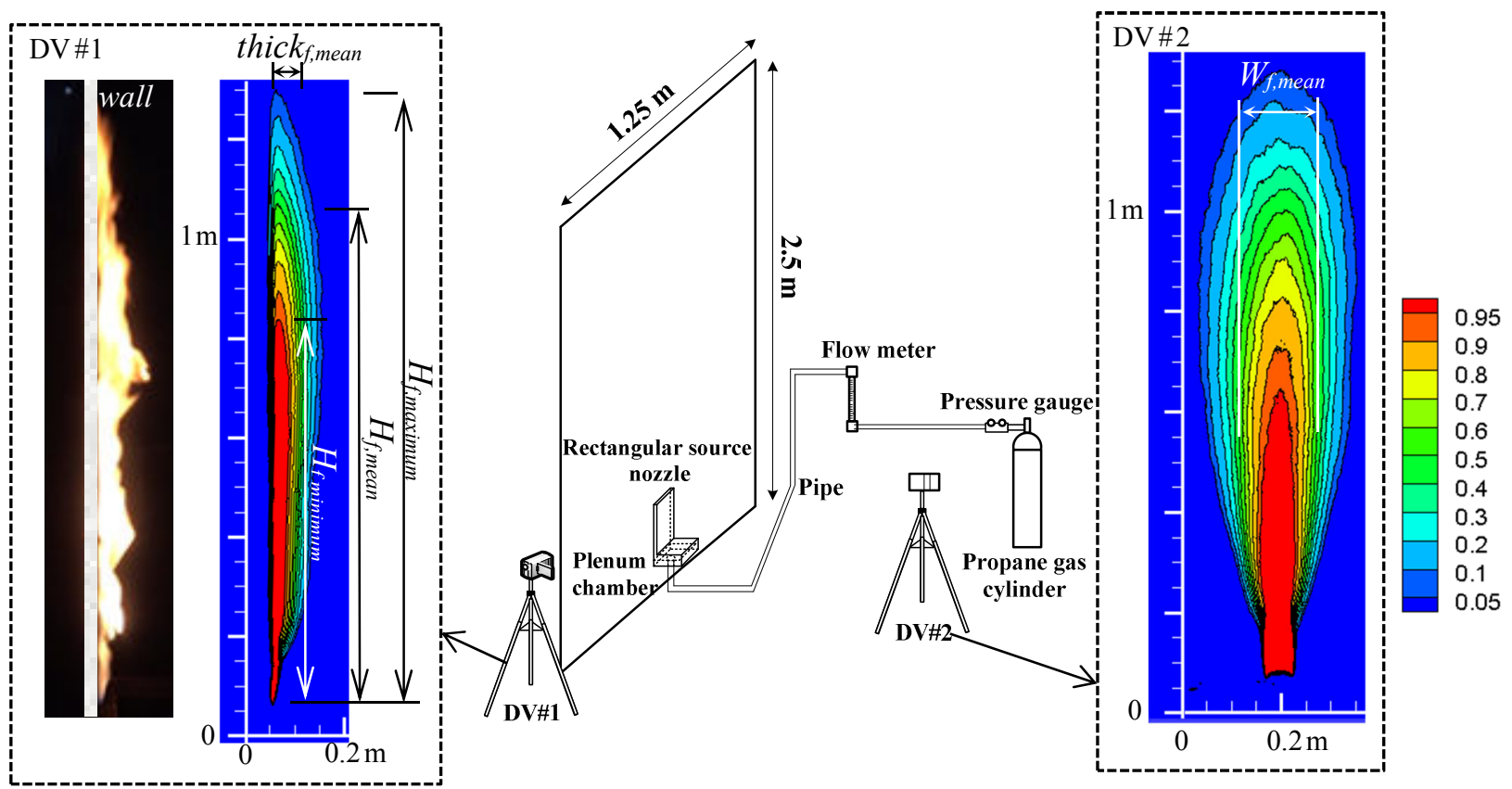

(a) 


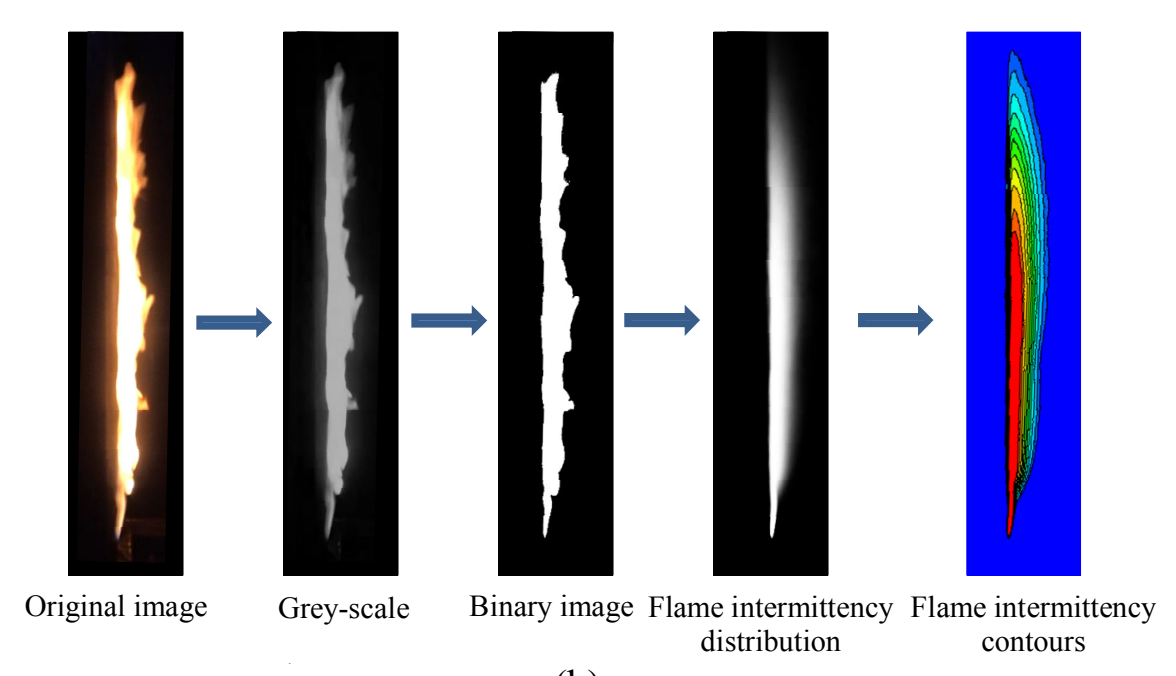

(b)

Fig. 2 (a) Experimental setup and typical flame intermittency contours for wall attached buoyancy driven turbulent flames (nozzle: $47.75 \mathrm{~mm} \times 5.97 \mathrm{~mm}$; heat release rate: $19.64 \mathrm{~kW}$ ); (b)

Determination of flame morphologic parameters based on image processing.

Here, we concentrated on buoyancy-driven (flame height increases with an increase in the heat release rate) turbulent flames and two non-dimensional parameters, the flame Froude number [37] and the flame Grashof number $(G r)$ [38-40] were used to determine the flow characteristics of the experimental conditions. In the calculation of the flame Froude number $F r_{f}, d$ was replaced by the equivalent diameter of the burner. For a buoyancy-driven flame, $F r_{f}<5$ [37], and the turbulence criterion requires that $G r \geq G r_{c r i t} \approx 2 \times 10^{9}$ [39] where $G r_{c r i t}$ is the critical flame Grashof number. Table 1 shows all the experimental conditions. Each case was repeated three times and the averaged values were used for analysis.

Two Digital Videos with $1920 \times 1280$ pixels (as shown in Fig. 2) were used during the experiments to record the flame at $25 \mathrm{fps}$. One was positioned perpendicular to the shorter side of the nozzle (DV\#1) to record the flame height and the flame thickness, and the other one was positioned perpendicular to the longer side of the nozzle (DV\#2) for recording the flame width. In this work, the macroscopic flame characteristics were focused. Due to time-fluctuating nature of the buoyant flame, an average method is 
needed to be obtain the flame macroscopic dimensions. Flame contours were then obtained by applying the image average processing method (Otsu method [41]) employing MATLAB program as done in [24]. Firstly, the recorded flame videos (30 s for each case) were decompressed into consecutive frames $(25 \times$ $30=750$ frames). Secondly, each frame was converted to a gray scale image and then to a binary image (Fig. 2b). Finally, the flame intermittency contour was obtained, as shown in Fig. 2b, by averaging the binary values at each pixel point of the binary image for the 750 consecutive frames. The reference length scales were calibrated in advance for each test. It is noted that the fluctuation frequency of such buoyant flame is normally in the range of 3-8 HZ [42]. So, the camera with normal frame speed of 25 fps is sufficient to capture the average flame characteristics from 750 consecutive frames. Thus the flame dimensions were accurately gained from the pixel length from the experimental flame images. The values of flame height, flame width and flame thickness were quantified based on the intermittency [24, 43-45] as illustrated in Fig. 2a. This method has been successfully used in defining the flame length of a horizontally oriented flames [24], vertical free line-source flames [44] and line-source flames with air entrainment constraint by two parallel side walls [45], which provided objective quantifications of these flame morphologic parameters.

Table 1 Summary of experimental conditions of both wall attached flames and free flames.

\begin{tabular}{|c|c|c|c|c|c|c|c|c|c|c|c|c|c|}
\hline \multirow{3}{*}{$\begin{array}{l}\text { Test } \\
\text { case }\end{array}$} & \multirow{3}{*}{$\begin{array}{l}\text { Test } \\
\text { No. }\end{array}$} & \multicolumn{12}{|c|}{ Nozzle dimension $L(\mathrm{~mm}) \times W(\mathrm{~mm})$} \\
\hline & & \multicolumn{3}{|c|}{$16.88 \times 16.88$} & \multicolumn{3}{|c|}{$47.75 \times 5.97$} & \multicolumn{3}{|c|}{$71.25 \times 4$} & \multicolumn{3}{|c|}{$142.5 \times 2$} \\
\hline & & $\begin{array}{c}u_{0} \\
(\mathrm{~m} / \mathrm{s})\end{array}$ & $\underset{(\mathrm{kW})}{\dot{Q}}$ & $\underset{(\mathrm{m})}{H_{f, \text { mean }}}$ & $\begin{array}{c}u_{0} \\
(\mathrm{~m} / \mathrm{s})\end{array}$ & $\underset{(\mathrm{kW})}{\dot{Q}}$ & $\frac{H_{f, \text { mean }}}{(\mathrm{m})}$ & $\begin{array}{c}u_{0} \\
(\mathrm{~m} / \mathrm{s})\end{array}$ & $\underset{(\mathrm{kW})}{\dot{Q}}$ & $\frac{H_{f, \text { mean }}}{(\mathrm{m})}$ & $\begin{array}{c}u_{0} \\
(\mathrm{~m} / \mathrm{s})\end{array}$ & $\underset{(\mathrm{kW})}{\dot{Q}}$ & $\begin{array}{c}H_{\text {f,mean }} \\
(\mathrm{m})\end{array}$ \\
\hline \multirow{6}{*}{ 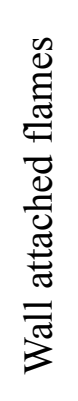 } & 1 & 0.096 & 2.23 & 0.419 & 0.096 & 2.23 & 0.482 & 0.096 & 2.23 & 0.416 & 0.096 & 2.23 & 0.295 \\
\hline & 2 & 0.144 & 3.35 & 0.495 & 0.143 & 3.35 & 0.506 & 0.143 & 3.35 & 0.528 & 0.143 & 3.35 & 0.397 \\
\hline & 3 & 0.191 & 4.46 & 0.554 & 0.191 & 4.46 & 0.615 & 0.191 & 4.46 & 0.631 & 0.191 & 4.46 & 0.507 \\
\hline & 4 & 0.268 & 6.25 & 0.641 & 0.268 & 6.25 & 0.675 & 0.268 & 6.25 & 0.696 & 0.268 & 6.25 & 0.638 \\
\hline & 5 & 0.383 & 8.93 & 0.743 & 0.383 & 8.93 & 0.778 & 0.383 & 8.93 & 0.778 & 0.383 & 8.93 & 0.784 \\
\hline & 6 & 0.459 & 10.71 & 0.807 & 0.459 & 10.71 & 0.839 & 0.459 & 10.71 & 0.830 & 0.459 & 10.71 & 0.838 \\
\hline
\end{tabular}




\begin{tabular}{|c|c|c|c|c|c|c|c|c|c|c|c|c|c|}
\hline & 7 & 0.574 & 13.39 & 0.873 & 0.574 & 13.39 & 0.907 & 0.574 & 13.39 & 0.914 & 0.574 & 13.39 & 0.920 \\
\hline & 8 & 0.727 & 16.96 & 0.918 & 0.727 & 16.96 & 0.938 & 0.727 & 16.96 & 0.965 & 0.727 & 16.96 & 0.964 \\
\hline & 9 & 0.842 & 19.64 & 0.977 & 0.842 & 19.64 & 1.013 & 0.842 & 19.64 & 0.997 & 0.842 & 19.64 & 1.024 \\
\hline \multirow{6}{*}{ 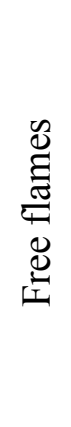 } & 1 & 0.469 & 11.29 & 0.640 & 0.469 & 11.29 & 0.650 & 0.469 & 11.29 & 0.598 & 0.469 & 11.29 & 0.510 \\
\hline & 2 & 0.657 & 15.81 & 0.709 & 0.656 & 15.81 & 0.702 & 0.750 & 18.07 & 0.695 & 0.657 & 15.81 & 0.600 \\
\hline & 3 & 0.844 & 20.32 & 0.759 & 0.844 & 20.32 & 0.732 & 1.032 & 24.84 & 0.764 & 0.938 & 22.58 & 0.623 \\
\hline & 4 & 1.032 & 24.84 & 0.803 & 1.031 & 24.84 & 0.779 & 1.219 & 29.36 & 0.825 & 1.219 & 29.36 & 0.730 \\
\hline & 5 & 1.220 & 29.36 & 0.840 & 1.220 & 29.36 & 0.832 & 1.313 & 31.62 & 0.842 & 1.501 & 36.13 & 0.791 \\
\hline & 6 & & & & 1.407 & 33.87 & 0.899 & & & & & & \\
\hline
\end{tabular}

\section{Results and Discussion}

In this section, correlations for the morphologic characteristics of wall attached flames (flame height, flame fluctuations, flame width and flame thickness) were discussed and related to those of free flames.

\subsection{Flame height}

The minimum, mean, maximum flame heights were defined as the point where flame intermittencies are $0.95,0.5$ and 0.05 , respectively as obtained from the flame intermittency contours (Fig. 2). Figure 3 plots the mean flame height (based on the intermittency of 0.5) against the $H R R$ for both free flames and wall attached flames of four rectangular nozzles. Figure 3 shows that the mean flame height of the wall attached flame is much larger than that of free flames for the same $H R R$. Their difference increases with increasing heat release rate. It is noted that for the wall attached flames, the flame height of the linear nozzle $0.1425 \mathrm{~m} \times 0.002 \mathrm{~m}$ is lower than that of the other nozzles at small heat release rates, but there is no great difference in the flame heights between the four nozzles at higher heat release rates. For the free flames, the flame height of the linear nozzle $0.1425 \mathrm{~m} \times 0.002 \mathrm{~m}$ is lower than that of the other nozzles in the whole $H R R$ range of this work. This is because that the burner dimension has an important effect on the air entrainment, and the linear nozzle $0.1425 \mathrm{~m} \times 0.002 \mathrm{~m}$ has a larger perimeter to entrain more air 
than the other burners.

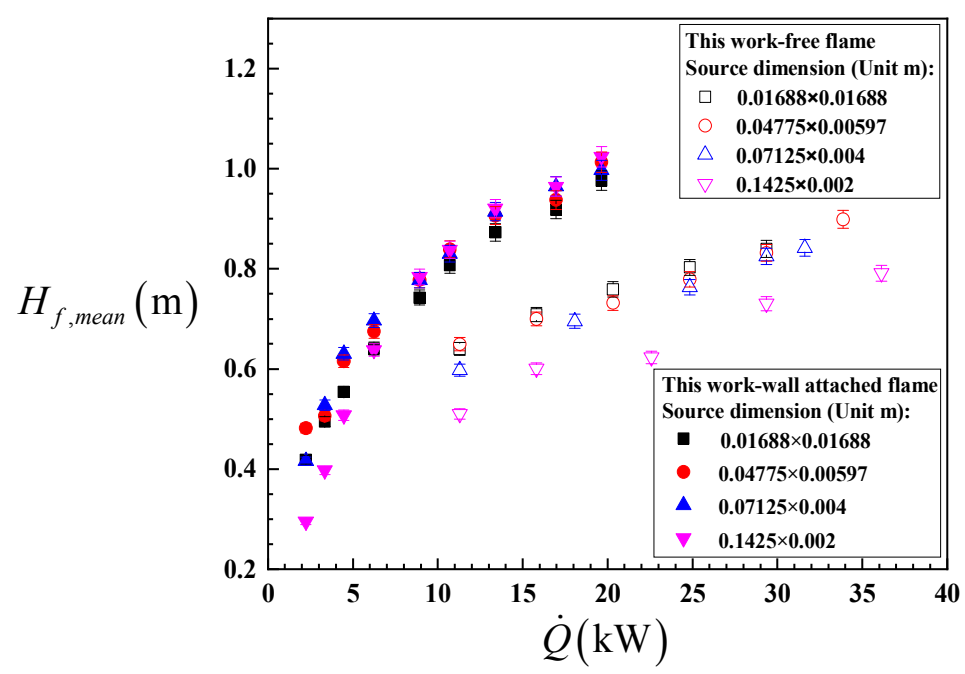

Fig. 3 Variation of mean flame height (based on the 0.5 flame intermittency) with $H R R$ for both

\section{free flames and wall attached flames.}

To compare in a meaningful way the differences in the entrainment between free flames and wall attached flames, we normalized and plotted the flame height data in Figs. 4(a) and 4(b) respectively.

For free flames (Fig. 4(a)) of a rectangular source of size $L$ and $W$, the flame height was normalized by the perimeter $2(L+W)$ which was used as the length scale and the corresponding non-dimensional equations were proposed as:

$$
\begin{gathered}
\frac{H_{f}}{2(L+W)}=\text { function }\left(\frac{\dot{Q}}{\rho_{\infty} C_{p} T_{\infty} \sqrt{g}[2(L+W)]^{5 / 2}}\right) \\
\frac{\dot{Q}}{\rho_{\infty} C_{p} T_{\infty} \sqrt{g}[2(L+W)]^{5 / 2}}=\dot{Q}_{\text {free }}^{*}
\end{gathered}
$$

The data in $[38,44,45]$ obtained by the same method as the one in this work are also shown in Fig. 4(a) for a comparison.

For the wall attached flames (Fig. 4(b)), we used their mirror image (Eq. (2)) to plot the data as it was usually done [46]. The data in [25] obtained by the same method as the one in this work are also 
shown in Fig. 4(b) for a comparison. In this case the appropriate effective perimeter was $2(L+2 W)$ and the effective heat release rate was taken as $2 \dot{Q}$ :

$$
\begin{gathered}
\frac{H_{f}}{2(L+2 W)}=\text { function }\left(\frac{2 \dot{Q}}{\rho_{\infty} C_{p} T_{\infty} \sqrt{g}[2(L+2 W)]^{5 / 2}}\right) \\
\frac{2 \dot{Q}}{\rho_{\infty} C_{p} T_{\infty} \sqrt{g}[2(L+2 W)]^{5 / 2}}=\dot{Q}_{\text {wall }}^{*}
\end{gathered}
$$

Regarding Figs. 4(a) and 4(b), we can make the following observations:

(1) For both cases, two regimes for the normalized flame height are observed: one having a $2 / 3$ power dependence on the normalized HRR for low HRRs and the second having a 2/5 power dependence on the normalized HRR for large HRRs as also observed in similar plots in the literature [47]. The first regime corresponds to a two-dimensional plume and the second regime to an axisymmetric three-dimensional plume. For the first regime, it is noted that, for the line nozzle case ( $L$ is much larger than $W$ ) of wall attached flames, the correlation can be rearranged as $H_{f, \text { mean }}=0.049(\dot{Q} / L)^{2 / 3}$ which is close to the previous correlation $H_{f, \text { mean }}=0.042(\dot{Q} / L)^{2 / 3}$ [48], and the flame height of a wall attached buoyancy driven turbulent flame is about 1.85 times of that of a free flame with the same nozzle dimension and the same heat release rate. It is also noted that, the transition behavior from two-dimensional plume to the axisymmetric three-dimensional plume of the wall attached flames with increasing heat release rate can be clearly identified from relatively small $H R R s$ for the burners used in this work.

(2) For the second regime, we notice that the flame height is independent of the chosen length scale but it depends only on the $H R R$. In addition, the proportionality coefficient is 3.66 for the free flames $\left(0.39<\dot{Q}_{\text {free }}^{*}<22.51\right)$ and 3.89 for the wall attached flames $\left(0.30<\dot{Q}_{\text {wall }}^{*}<10.97\right)$, which shows that the restriction of the wall has no great effect on the normalized flame height by using the new definition of 
dimensionless heat release rate. And this means that the flame height for a wall attached source with a dimension $L \times W$ and $H R R \dot{Q}$ is almost equal to the flame height for a free source with a dimension $L \times$ $2 W$ and $H R R 2 \dot{Q}$. The reason is due to the following competing effects: For wall attached flames, it is expected, compared to free flamets, that the air entrainment rate and fluctuations will decrease in the presence of the wall which impedes large scale eddies (as shown in Fig. 6 later). Reduced air entrainment would tend to increase the flame height but reduced fluctuations would tend to decrease it because they induce better mixing and thus more efficient combustion. It is also noted that the flame height of a wall attached flame is about 1.4 times of that of a free flame with the same source dimension and the same $H R R$. For free flames, the correlation can be rearranged as $H_{f, \text { mean }}=0.22 \dot{Q}^{2 / 5}$ which is very close to Heskestad's correlation $[46,49] H_{f, \text { mean }}=0.235 \dot{Q}^{2 / 5}-1.02 D$ with small $D$.

(3) Transition from the two-dimensional ( $2 / 3$ power) to the three-dimensional ( $2 / 5$ power) regime occurs at the normalized heat release rate 0.39 for free flames and the normalized heat release rate 0.30 for wall attached flames. It is noted that there is some deviation of experimental data from the correlation around the critical non-dimensional $H R R$ value (0.4 0.6) in Fig. 4a, corresponding to the transition from two-dimensional to three-dimensional plume which would still have some uncertainty herein. However, the critical non-dimensional $H R R$ value is the best point that could be found from the intersection of the two correlation lines of the two regimes based on the data available. For the first regime, the proportionality coefficient is 4.70 (based on the data of this work and the data in $[38,44,45]$, $0.035<\dot{Q}_{\text {free }}^{*}<0.39$ ) for the free flames and 5.47 (based on the data of this work and the data in [25], $0.003<\dot{Q}_{\text {wall }}^{*}<0.30$ ) for the wall attached flames.

Further analysis and differences of literature flame height data for free flames and wall attached flames are included in Appendix A, which also supports the two-regime behavior of the flame height, although the data obtained by different methods have some inherent difference. 


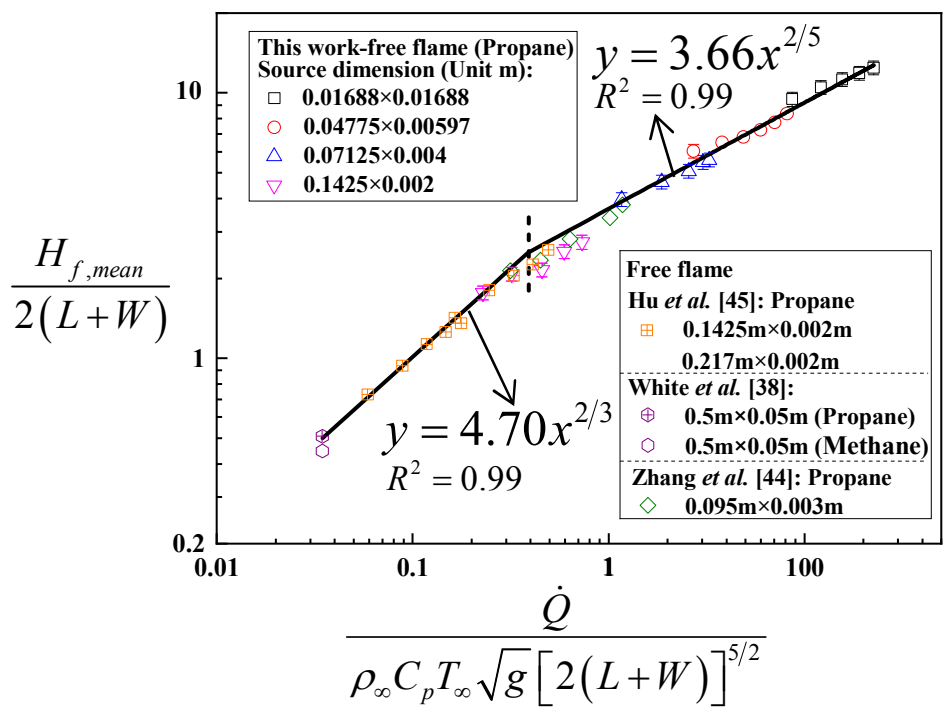

(a) free flame

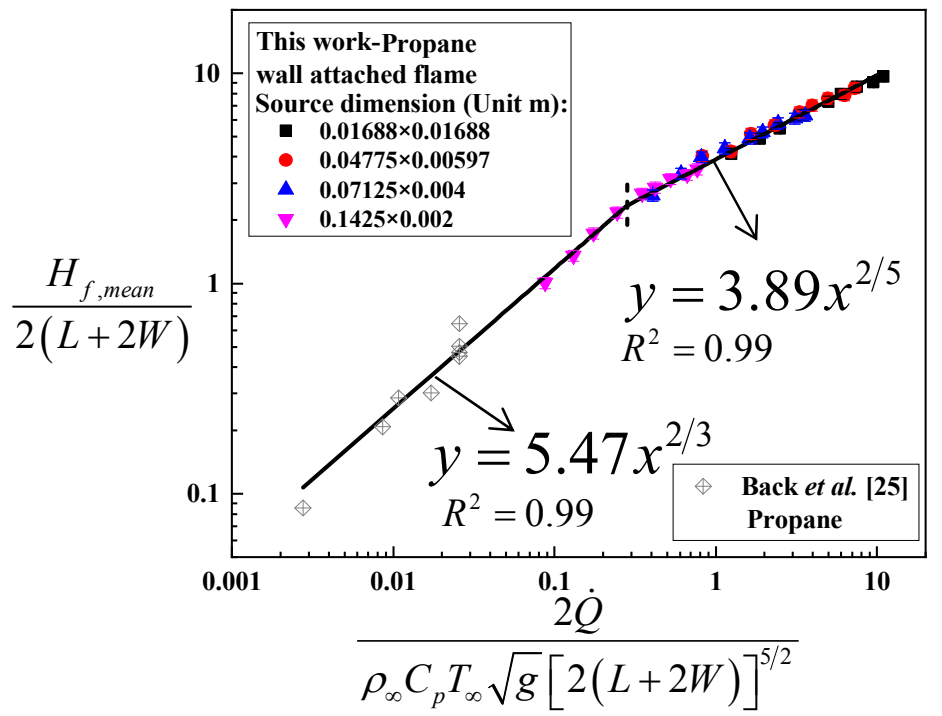

(b) wall attached flame

Fig. 4 Normalized mean flame height for wall attached flames and free flames based on Eq. (1) and Eq. (2) ("mirror" treatment), respectively, showing that the non-dimensional flame heights of both wall attached flames and free flames experience a two-dimensional to three-dimensional

\section{transition.}

In order to more clearly capture the difference in the flow field (hence air entrainment) between the wall-attached and the free flames, we performed Computational Fluid Dynamics (CFD) simulations of both these two types of flames for the source of $47.75 \mathrm{~mm} \times 5.97 \mathrm{~mm}$ with a $H R R$ of $8.93 \mathrm{~kW}$ by using 
Fire Dynamics Simulator (FDS) (Version: 6.7.0) Large Eddy Simulation (LES) tool. The default simple chemistry, mixing-controlled combustion model (single-step) was used for the reaction in the simulations [50]. This approach has been widely applied in modeling of buoyant turbulent flame macroscopic characteristics $[51,52]$. Here, it considers a single fuel species that is composed primarily of $\mathrm{C}, \mathrm{H}, \mathrm{O}$, and $\mathrm{N}$ that reacts with oxygen in one mixing controlled step to form $\mathrm{H}_{2} \mathrm{O}, \mathrm{CO}_{2}$, soot, and $\mathrm{CO}$ [50], which is applicable for the fuel of propane in the present study. Moreover, it is a fundamental methodology that for a given heat release rate, the flame morphologic characteristic parameter of non-premixed buoyancy driven turbulent flames was only controlled by the mixing (entrainment) of air with fuel [49, 53, 54]. Figure 5 showed the mesh size of the FDS simulations for both wall-attached and free flames. In the simulation, the smallest mesh size for the wall-attached flame case was $3 \mathrm{~mm} \times 3 \mathrm{~mm} \times 3 \mathrm{~mm}$, and the largest mesh size was $6 \mathrm{~mm} \times 6 \mathrm{~mm} \times 6 \mathrm{~mm}$ with 2.17 million meshes. The smallest mesh size and the largest mesh size for the free flame case were also $3 \mathrm{~mm} \times 3 \mathrm{~mm} \times 3 \mathrm{~mm}$ and $6 \mathrm{~mm} \times 6 \mathrm{~mm} \times 6 \mathrm{~mm}$, respectively, with 3.64 million meshes.

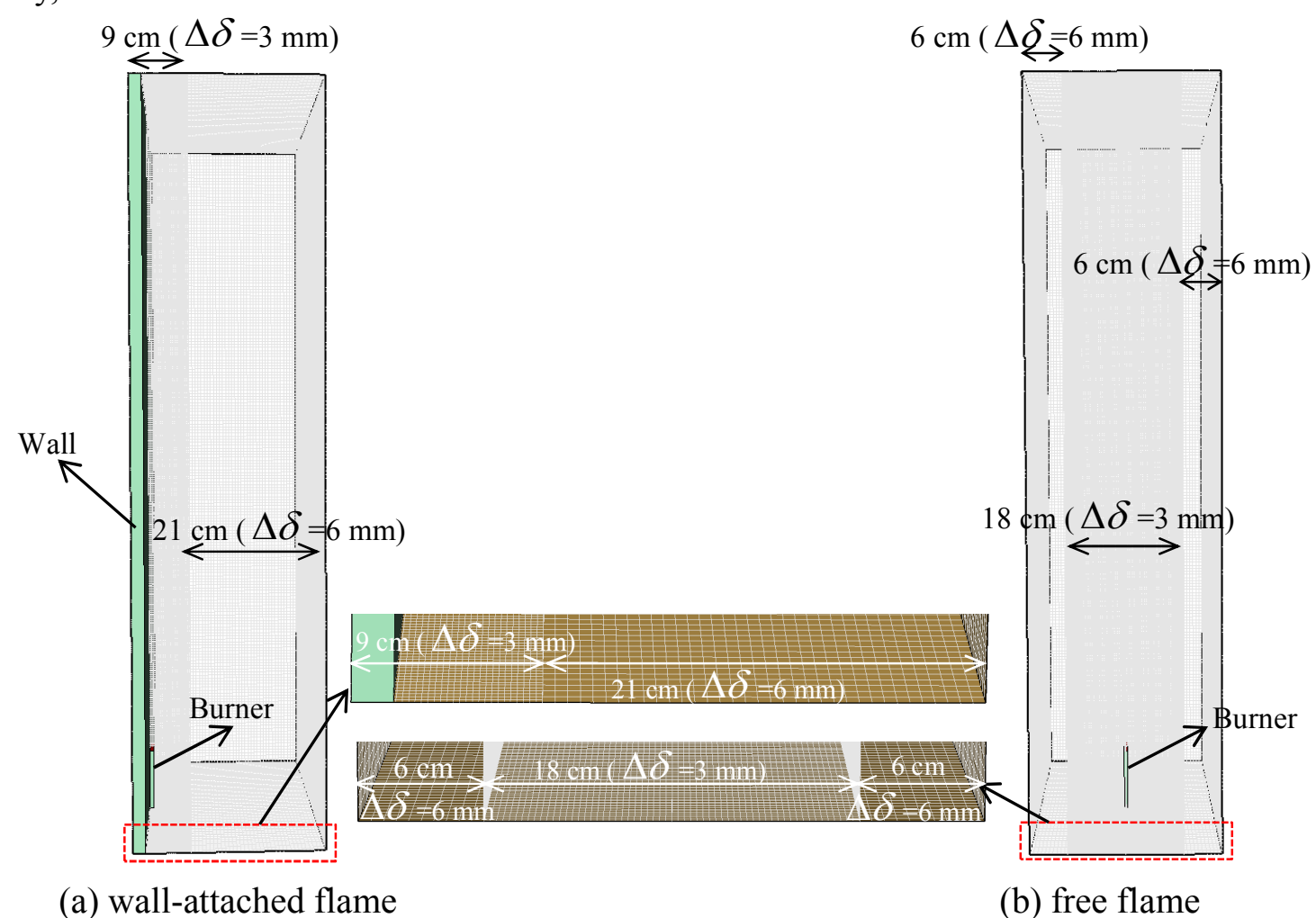




\section{Fig. 5 CFD simulation setup and mesh sizes.}

Figure 6 shows the temperature profiles and velocity vectors within a cycle from the view normal to the short side of the nozzle, where the blue lines are the streamlines. For the wall-attached flame, from Fig. 6a, we can see that the vortex only exits on the free side of the plume. At $12.66 \mathrm{~s}$, the first vortex appears at the flame low part and moves up over time. The vortex disappears from the plumes after 0.09 s. For the free flame, Fig. $6 \mathrm{~b}$ shows that the vortexes exist symmetrically on the both sides of the plume. After $0.06 \mathrm{~s}$, the vortexes exist at both the lower and upper parts of the plume. Subsequently, the size of the vertex at the lower position decreases, whereas the size of the vertex at the upper position increases over the time (12.72 s-12.81 s in Fig. 6b). By comparing Fig. 6a and Fig. 6b, we can see that the size of the large-scale vertex of free flame is larger than that of the wall-attached flame and that, based on our observation, the vertex of the free flame exits over the whole cycle time. The plume surface of the free flame is more turbulent than that of the wall-attached flame. All the above observed phenomena may lead to the difference of the air entrainment between the free flame and the wall-attached flame. 

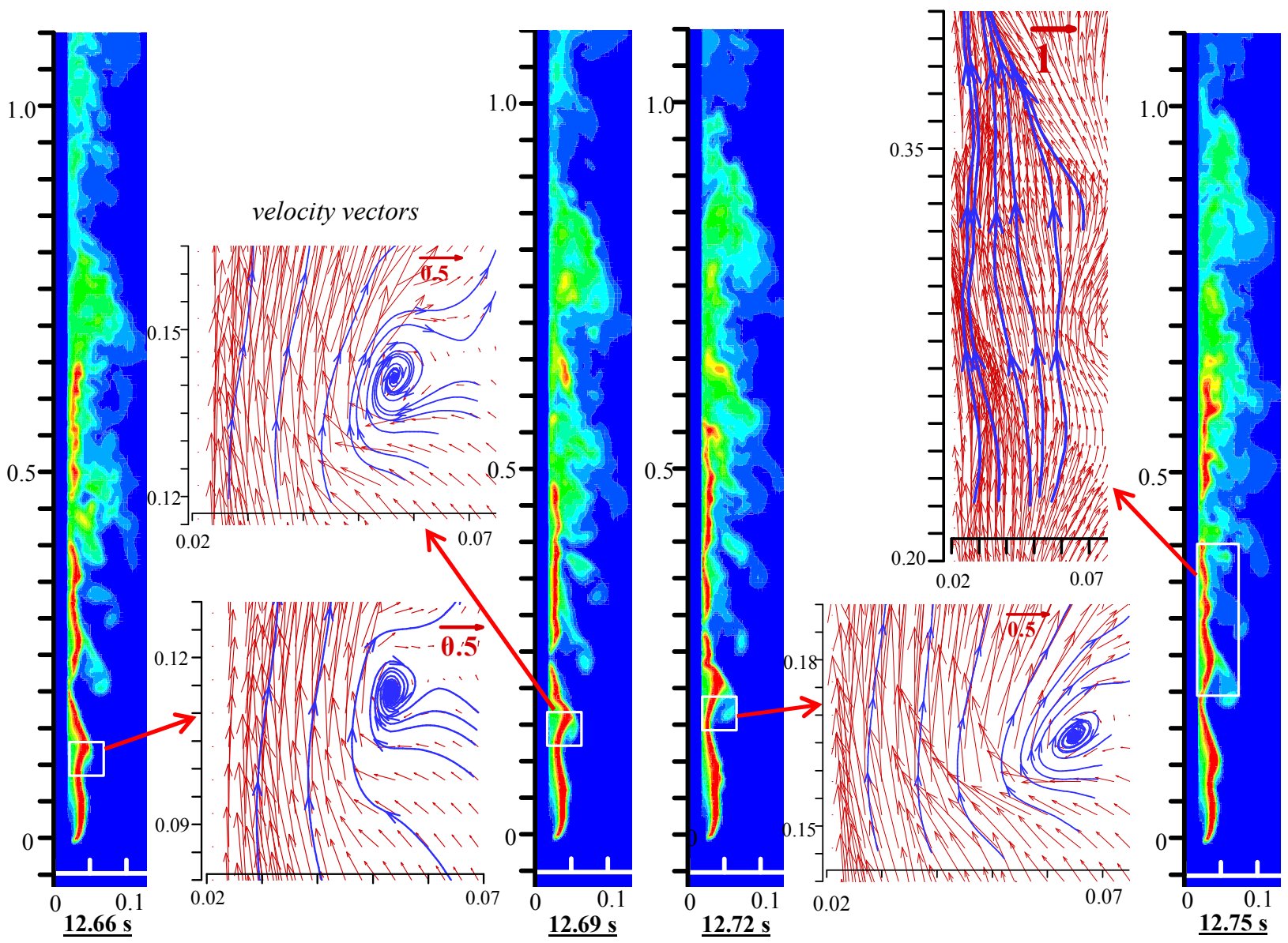

(a) wall-attached flame 

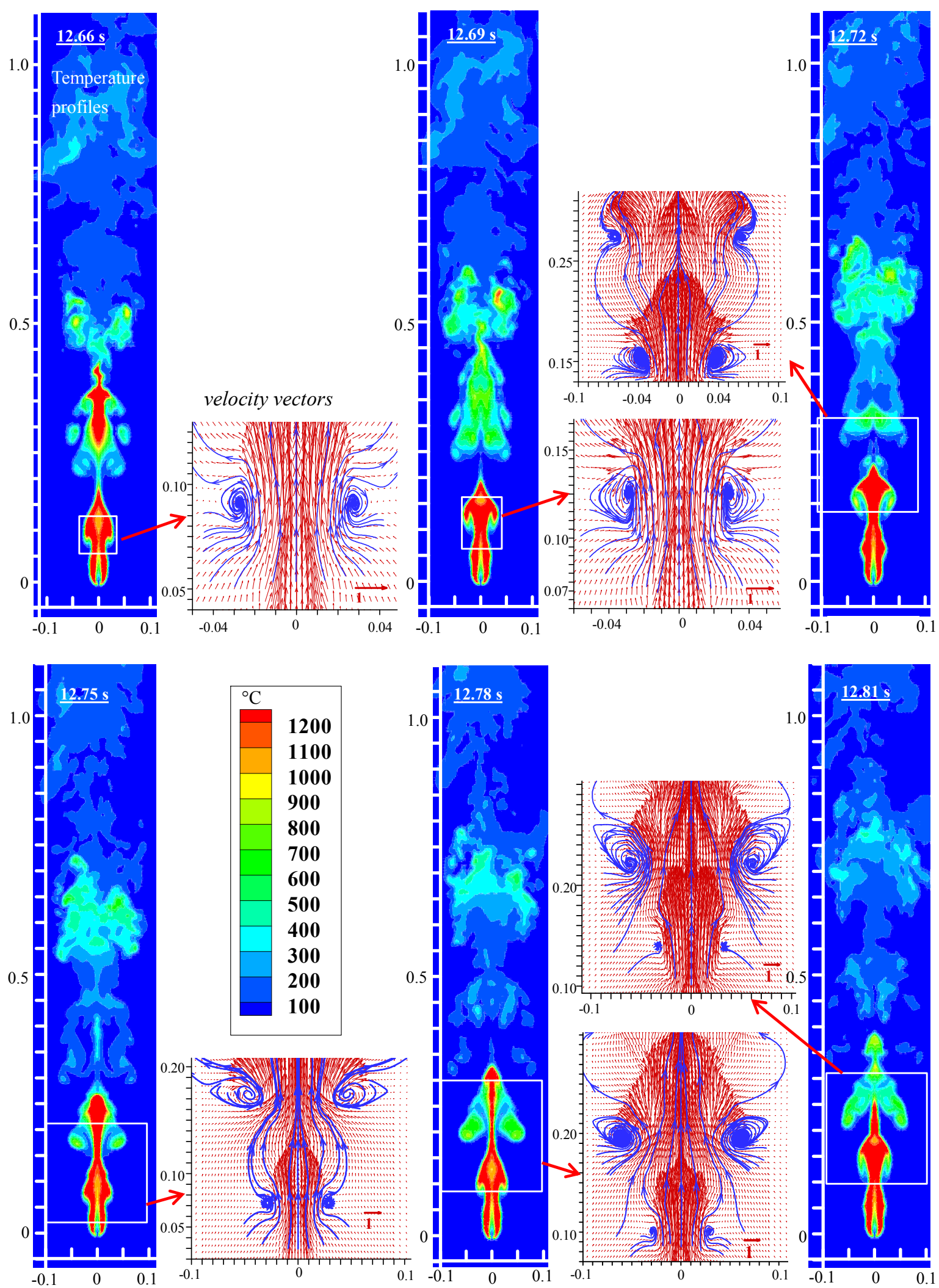

(b) free flame 
Fig. 6 FDS simulation results of temperature profiles and velocity vectors of both the free flame and the wall attached flame for the source of $47.75 \mathrm{~mm} \times 5.97 \mathrm{~mm}$ with heat release rate of $8.93 \mathrm{~kW}$.

In the following sections only the results for the $2 / 5$ power regime (see Figs. 4(a) and 4(b)), in which the flame height is independent of the chosen length scale but depends only on the heat release rate, are discussed for the free flames and the wall attached flames to have a fair comparison.

\subsection{Flame height fluctuations}

We plot in Fig. 7 the flame fluctuations as expressed by the ratio of maximum flame height $H_{f, \text { maxim um }}$ (0.05 intermittency) to the minimum (continuous) flame height $H_{f, \text { minimum }}(0.95$ intermittency) against the non-dimensional HRR (for the free flame $\dot{Q}^{*}=\dot{Q}_{\text {free }}^{*}\left(\right.$ Eq. 1b), for the wall attached flame $\dot{Q}^{*}=\dot{Q}_{\text {wall }}^{*}$ (Eq. $2 b)$ ). It can be seen that, for the free flames, this ratio is about 2 . For the wall attached flames, the ratio is smaller (1.4 to about 1.8) than that for the free flames, and decreases with increasing source aspect ratio. This indicates that free flames have a larger flame height fluctuation than that of the wall attached flames.

This result is also corroborated by Fig. 8 showing the ratio of the mean ( 0.5 intermittency) to minimum (continuous, 0.95 intermittency) flame height. It can be seen that, for the free flames, this ratio is almost constant about 1.46. For the wall attached flames, this ratio is smaller than that of the free flames and decreases with increasing source aspect ratio.

The reduced flame fluctuations coupled with the reduced entrainment in wall attached flames has helped to explain why wall attached flame heights appropriately normalized in section 3.1 are almost the same as free flames. 


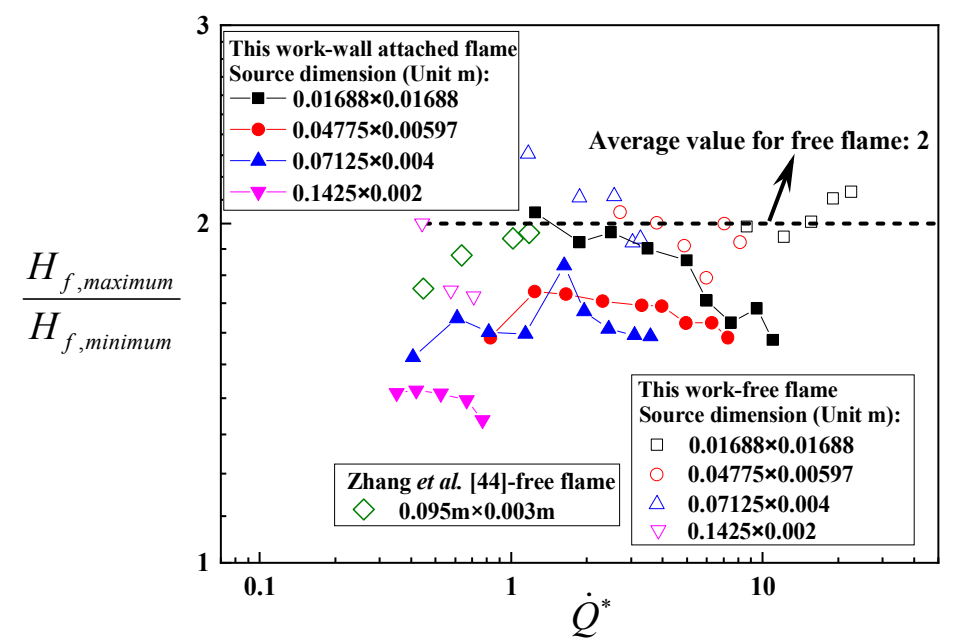

Fig. 7 Flame height fluctuation range for free flames and wall attached flames, showing that the flame height fluctuation of wall attached flame is smaller than that of free flame, and decreases with the increasing of the burner aspect ratio.

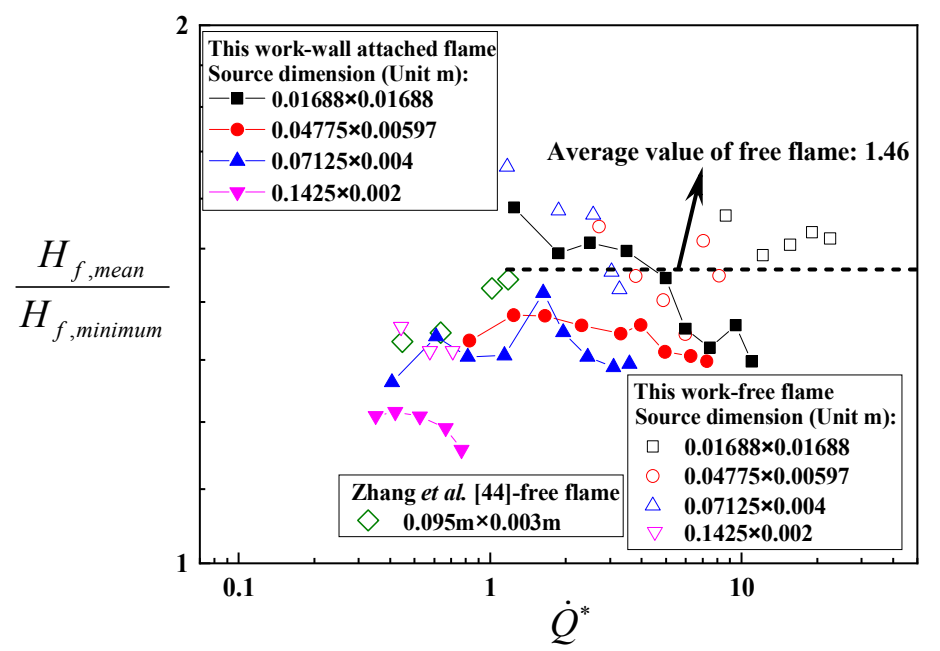

Fig. 8 The ratio of the mean flame height to the minimum flame height for free flames and wall attached flames which has the similar behavior with the flame height fluctuation range in Fig. 7.

\subsection{Flame width}

Figure 9 presents the maximum mean flame width $W_{f \text {,mean }}$ (based on the 0.5 flame intermittency, see illustration in Fig. 2) normalized by the mean flame height. It shows that the normalized flame width of a free buoyancy driven turbulent flame decreases with decreasing source aspect ratio. Compared with the 
flame thickness of a free flame (shown later in section 3.4, Fig. 11), we can observe that the flame width and the flame thickness are almost the same for the three burners with relatively smaller aspect ratios. This means that the flames of these sources have reached nearly axisymmetric conditions for large heat release rates. However, for the largest aspect ratio burner, the normalized flame width is slightly larger than the normalized flame thickness. Figure 9 shows that for a wall attached flame, the higher the aspect ratio, the larger the flame width. However, the difference between the four source aspect ratios decreases with increasing HRR (or the flame height). This finding is different from that observed for the behavior of the flame thickness of a wall attached flame (section 3.4, Fig. 11), which is due to the fact that the effect of the nozzle length (larger than the source width) still exists especially for larger aspect ratios. The normalized flame width $W_{f, \text { mean }} / H_{f, \text { mean }}$ of wall attached flames is slightly smaller than that of free flames.

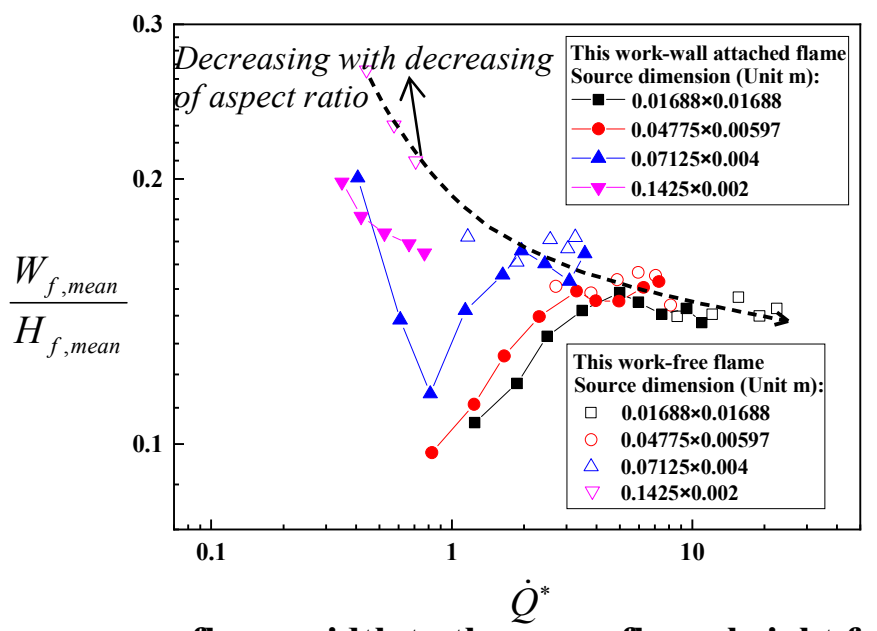

Fig. 9 Ratio of maximum mean flame width to the mean flame height for both free flames and wall attached flames.

The normalized flame width by using the appropriate effective perimeter is correlated with the nondimensional HRR as shown in Fig. 10. The results indicate that the data for both free flames and wall attached flames almost coincide with each other. A general correlation can be obtained for both free flames and wall attached flames $\left(0.30<\dot{Q}_{\text {free }}^{*}<22.51\right)$ as shown in Fig. 10 , which can be used to estimate the damage area in the lateral direction. 


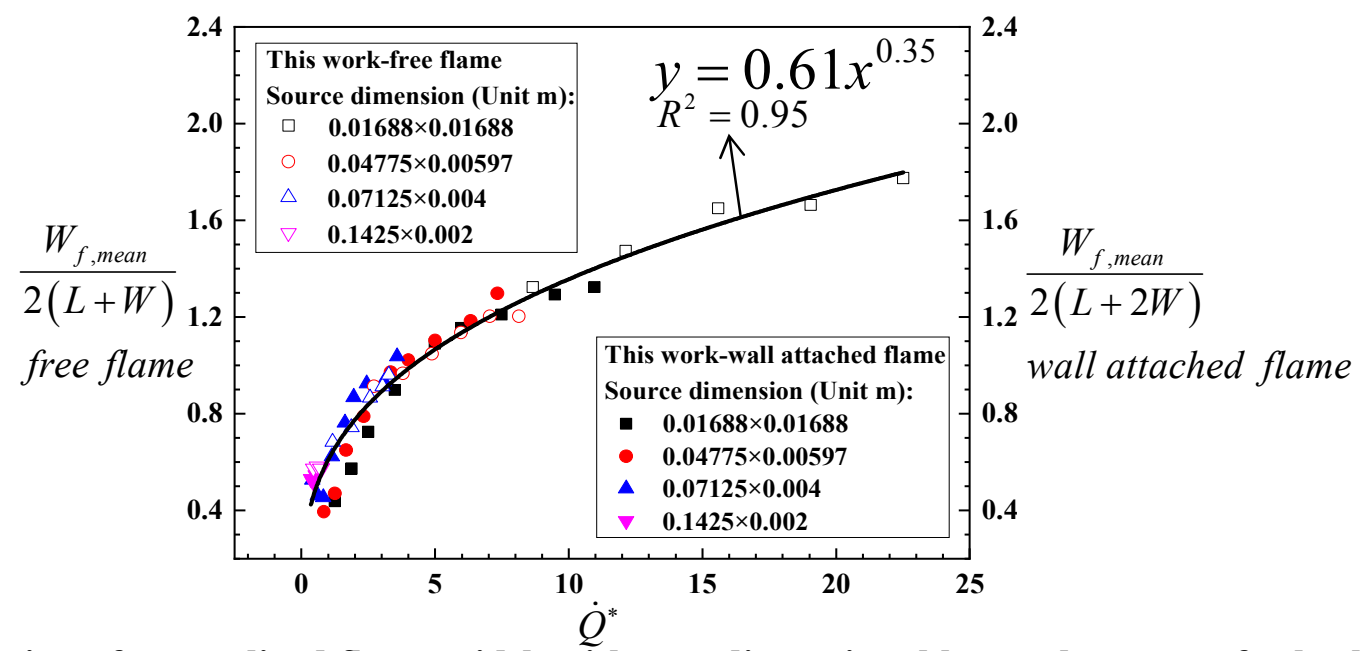

Fig. 10 Correlation of normalized flame width with non-dimensional heat release rate for both free

\section{flames and wall attached flames.}

\subsection{Flame thickness}

Figure 11 shows the maximum mean flame thickness thick $_{f, \text { mean }}$ (based on the 0.5 flame intermittency, see illustration in Fig. 1) normalized by the mean flame height. It is noted that the ratio of flame thickness to flame height reflects in a manner the diffusion and mixing as well as fluctuation, which is a basic feature of diffusive combustion and flame instability as a nature of buoyant flow. The comparison of this ratio between the wall attached buoyancy driven turbulent flames and the free flames can reflect the differences between the air entrainment in these two cases. For a wall attached flame, one can imagine that the flame thickness is half of that for a free flame, so we plot 2 thick $_{f, \text { mean }} / H_{f, \text { mean }}$ instead of thick $k_{f, \text { mean }} / H_{f, \text { mean }}$ to compare with the flame thickness of free flames.

For the free flames, thick ${ }_{f, \text { mean }} / H_{f \text {,mean }}$ is slightly decreased with decreasing source aspect ratio (the source width increased and source length decreased). The influence of the source width decreases with increasing flame height. However, the effect of the source length still exists, and the air entrainments from this side decreases with decreasing nozzle aspect ratio (the source length decreases with the decreasing of the nozzle aspect ratio) leading to the decreasing of the flame thickness. 
For the wall attached flames, 2 thick $_{f, \text { mean }} / H_{f, \text { mean }}$ of the four burners are smaller than thick $_{f, \text { mean }} / H_{f, \text { mean }}$ of the free flames especially for larger aspect ratios. We believe that this behavior is due to decreased fluctuations when the wall is present as discussed in section 3.2. In addition, Fig. 11 shows that 2 thick $_{f, \text { mean }} / H_{f, \text { mean }}$ decreases with an increase in the source aspect ratio, which is consistent with the observations in Fig. 6.

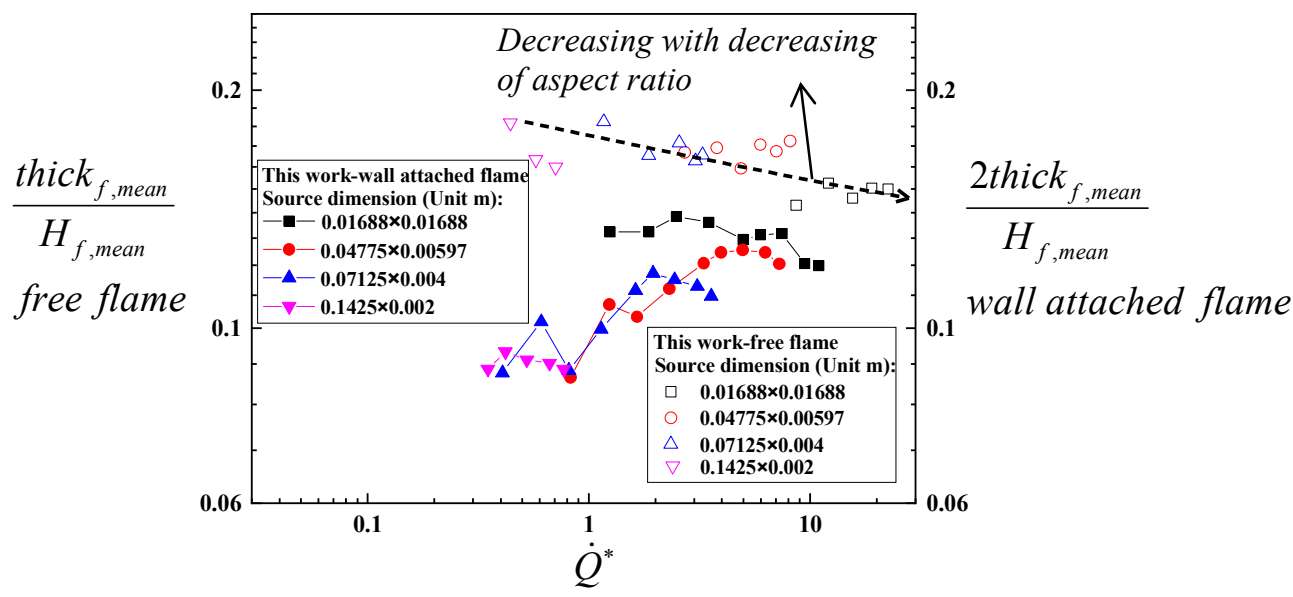

Fig. 11 Ratio of maximum mean flame thickness to the mean flame height for both free flames and wall attached flames.

We further plot the normalized flame thickness by using the appropriate effective perimeter with the effective non-dimensional $H R R$ as shown in Fig. 12. For the free flames, a correlation is obtained for $0.39<\dot{Q}_{\text {free }}^{*}<22.51$

$$
\frac{\text { thick }_{f, \text { mean }}}{2(L+W)}=0.62\left(\frac{\dot{Q}}{\rho_{\infty} C_{p} T_{\infty} \sqrt{g}[2(L+W)]^{5 / 2}}\right)^{0.36}
$$

For the wall attached flames, a correlation is obtained as following for $0.30<\dot{Q}_{\text {wall }}^{*}<10.97$

$$
\frac{2 \text { thick }_{f, \text { mean }}}{2(L+2 W)}=0.44\left(\frac{2 \dot{Q}}{\rho_{\infty} C_{p} T_{\infty} \sqrt{g}[2(L+2 W)]^{5 / 2}}\right)^{0.45}
$$

The above correlations of the flame thickness can also be used to estimate the path length through the 
flame which is related to the radiative heat flux for evaluating the thermal impact to the wall as well as the radiation to nearby flammable objects.

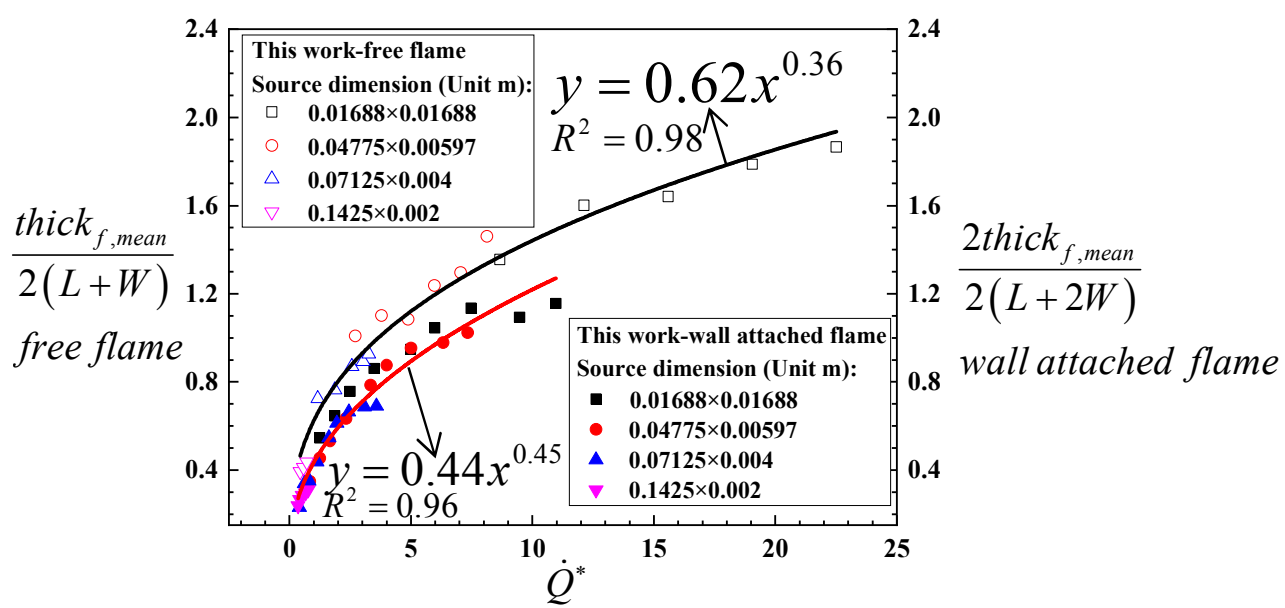

Fig. 12 Correlations of normalized flame thickness with non-dimensional heat release rate for both free flames and wall attached flames.

\section{Concluding remarks}

This paper investigates the flame morphologic characteristics of wall attached non-premixed buoyancy driven turbulent flames. Flame height and fluctuations, flame thickness and flame width of wall attached flames are quantified comprehensively and compared with those of free flames. Major findings include:

(1) The non-dimensional flame heights of wall attached flames also experience a two-dimensional to three-dimensional transition as free flames do, where the effective perimeter of the source is found to be an appropriate length scale for correlation. The critical non-dimensional heat release rate for this transition of the wall attached flames is smaller than that of the free flames (Fig. 4).

(2) The flame height fluctuations represented by the ratio of maximum to minimum flame heights of a wall attached flames are smaller than that of free flames, and it decreases with increasing source aspect ratio (Fig. 7). This behavior indicates relatively higher local mixing effectiveness and hence, less height 
is needed for air entrainment (or namely, less total entrained air is needed) for the wall attached flames to complete combustion, than the free flames. However, due to the competition of reduced fluctuation and reduced air entrainment of wall attached flames, both cases have the similar non-dimensional flame height as shown in Fig. 4.

(3) The ratio of flame width to flame height of wall attached flames is slightly smaller than that of free flames especially for larger aspect ratios (Fig. 9). The ratio of flame thickness to flame height of wall attached flames is smaller than that of free flames, and it decreases with increasing source aspect ratio (Fig. 11). Correlations are proposed for flame width (Fig. 10) and flame thickness (Fig. 12, Eq. (3) and (4)) where the effective perimeter of the source is also found to be an appropriate length scale.

This work provides important and basic knowledge for the effect of wall on flame characteristics of vertical gaseous non-premixed buoyancy driven turbulent flames, which could be referable widely for the design of gaseous fuel transportation systems as well as the assessment of risk and environmental impact of gas fuel transportation systems leakage in the urban. More work for various release direction and pressure of gas of wall attached buoyancy driven turbulent flames would be an interesting and important future work. We also notice that high speed camera could be beneficial to obtain more clearly the combustion characteristics, for example [55], especially the fast micro-scale flow behaviors inside the turbulent flame. This could also be interesting future work.

\section{Acknowledgement}

This work was supported jointly by Key Project of National Natural Science Foundation of China (NSFC) under Grant No. 51636008, Opening Funds of State Key Laboratory of Building Safety and Built Environment and National Engineering Research Center of Building Technology under Grant No. BSBE2018-05, China Postdoctoral Science Foundation under Grant no. 2019M652213, Newton Advanced Fellowship (RS: NA140102), Fok Ying Tong Education Foundation under Grant No. 151056, 
Fundamental Research Funds for the Central Universities under Grant No. WK2320000035 and WK2320000038 and China Scholarship Council under Program for Ph.D. Student Overseas Study Scholarship 2016 to Xiaolei Zhang, hosted by FireSERT at the Ulster University, UK.

\section{References}

[1] BP Statistical Review of World Energy, 67 $7^{\text {th }}$ edition, BP p.l.c., June, 2018.

[2] Wang Q, Tang F, Zhou Z, Liu H, Palacios A. Flame height of axisymmetric gaseous fuel jets restricted by parallel sidewalls: Experiments and theoretical analysis. Appl Energ 2017; 208: 1519-26.

[3] Wang Q, Tang F, Liu H, Zhou Z, Palacios A. Experimental investigation on the effect of a reduced pressure on the combustion characteristics and flame height of gaseous fuel jets in parallel sidewalls. Energ Fuel 2018; 32 (2): 2490-6.

[4] Zhang XL, Hu LH, Wang Q, Zhang XC, Gao P. A mathematical model for flame volume estimation based on flame height of turbulent gaseous fuel jet. Energ Convers Manage 2015; 103: 276-83.

[5] Tang, AK, Deng J, Cai T, Xu YM, Pan, JF. Combustion characteristics of premixed propane/hydrogen/air in the micro-planar combustor with different channel-heights. Appl Energ 2017; 203: $635-42$.

[6] Wierzbicki TA, Lee IC, Gupta AK. Combustion of propane with Pt and Rh catalysts in a meso-scale heat recirculating combustor. Appl Energ 2014; 130: 350-6.

[7] Kumar P, Mishra DP. Characterization of bluff-body stabilized LPG jet diffusion flame with $\mathrm{N}_{2}$ dilution. Energ Convers Manage 2008; 49: 2698-703.

[8] Akbari MH, Riahi P, Roohi R. Lean flammability limits for stable performance with a porous burner. Appl Energ 2009; 86: 2635-43.

[9] Rashwan SS, Ibrahim AH, Abou-Arab TW, Nemitallah MA, Habib MA. Experimental investigation 
of partially premixed methane-air and methane oxygen flames stabilized over a perforated-plate burner. Appl Energ 2016; 169: 126-37.

[10] Hughes L, Jong MD, Wang XQ. A generic method for analyzing the risks to energy systems. Appl Energ 2016; 180: 895-908.

[11] Su H, Zhang JJ, Zio E, Yang N, Li XY, Zhang ZJ. An integrated systemic method for supply reliability assessment of natural gas pipeline networks. Appl Energ 2018; 209: 489-501.

[12] Witkowski A, Rusin A, Majkut M, Rulik S, Stolecka K. Comprehensive analysis of pipeline transportation systems for $\mathrm{CO} 2$ sequestration. Thermodynamics and safety problems. Energ Convers Manage 2013; 76: 665-73.

[13] Rimkevicius S, Kaliatka A, Valincius M, Dundulis G, Janulionis R, Grybenas A, Zutautaite I. Development of approach for reliability assessment of pipeline network systems. Appl Energ 2012; 94: 22-33.

[14] Han ZY, Weng WG. Comparison study on qualitative and quantitative risk assessment methods for urban natural gas pipeline network. J Hazard Mater 2011; 189 (1-2): 509-18.

[15] Seleznev VE, Aleshin VV. Numerical analysis of fire risk at pipeline systems of industrial power facilities. Int J Pres Ves Pip 2006; 83 (4): 299-303.

[16] Palacios A, Casal J. Assessment of the shape of vertical jet fires. Fuel 2011; 90 (2): 824-33.

[17] Kang YH, Lu XF, Wang QH, Gan L, Ji XY, Wang H, Guo Q, Song DC, J PY. Effect of $\mathrm{H}_{2}$ addition on combustion characteristics of dimethyl ether jet diffusion flame. Energ Convers Manage 2015; 89: $735-48$.

[18] Shang FJ, Hu LH, Sun XP, Wang Q, Palacios A. Flame downwash length evolution of non-premixed gaseous fuel jets in cross-flow: Experiments and a new correlation. Appl Energ 2017; 198: 99-107.

[19] Lee WJ, Shin HD. Visual characteristics, including lift-off, of the jet flames in a cross-flow high- 
temperature burner. Appl Energ 2003; 76 (1-3): 257-66.

[20] Becker HA, Liang D. Effect of burner orientation and ambient airflow on geometry of turbulent free diffusion flames. Symp (Int) Combust 1981; 18: 1061-71.

[21] Peters N, Gottgens J. Scaling of buoyant turbulent jet diffusion flames. Combust Flame 1991; 85: $206-14$

[22] Johnson AD, Brightwell HM, Carsley AJ. A model for predicting the thermal radiation hazards from large-scale horizontally released natural gas jet fires. Trans IChemE 1994; 72: 157-66.

[23] Smith TL, Periasamy C, Baird B, Gollahalli SR. Trajectory and characteristics of buoyancy and momentum dominated horizontal jet flames from circular and elliptic burners. $J$ Energy Resour Technol 2005; 128 (4): 300-10.

[24] Zhang XL, Hu LH, Zhang XC, Tang F, Jiang Y, Lin YJ. Flame projection distance of horizontally oriented buoyant turbulent rectangular jet fires. Combust Flame 2017; 176: 370-6.

[25] Back G, Beyler C, Dinenno P, Tatem P. Wall incident heat flux distributions resulting from an adjacent fire. Fire Safety Science- Proceedings of the Fourth International Symposium 1994, 241-52.

[26] Delichatsios MA. Flame heights in turbulent wall fires with significant flame radiation. Combust Sci Technol 1984; 39: 195-214.

[27] Hasemi Y. Experimental wall flame heat transfer correlations for the analysis of upward wall flame spread. Fire Sci Technol 1984; 4: 75-90.

[28] Kulkarni AK. Radiative and total heat feedback from flames to surface in vertical wall fires. Exp Heat Transfer 1990; 3: 411-26.

[29] Jangi M, Dlugogorski BZ. On wall fire interaction in a small pool fire: A large-eddy simulation study. Fire Safety J 2017; 92: 199-209.

[30] Coutin M, Most JM, Delichatsios MA, Delichatsios MM. Flame heights in wall fires: effects of width, 
confinement and pyrolysis length. Fire Safety Science- Proceedings of the Sixth International Symposium 2000, 729-40.

[31] Quintiere JG, Cleary TG. Heat flux from flames to vertical surfaces, Fire Technol 1994; 30: 209-31.

[32] Gövert S, Mira D, Kok JBW, Vázquez M, Houzeaux G. Turbulent combustion modelling of a confined premixed jet flame including heat loss effects using tabulated chemistry. Appl Energ 2015; 156: $804-15$

[33] Hasemi Y, Tokunaga T. Some experimental aspects of turbulent diffusion flames and buoyant plumes from fire sources against a wall and in a corner of walls. Combust Sci Technol 1984; 40: 1-17.

[34] Wang Q, Hu LH, Tang F, Zhang XC, Delichatsios MA. Characterization and comparison of flame fluctuation range of a turbulent buoyant jet diffusion flame under reduced- and normal pressure atmosphere. Procedia Engineering 2013; 62: 211-8.

[35] Audouin L, Kolb G, Torero JL, Most JM. Average centerline temperatures of a buoyant pool fire obtained by image processing of video recordings. Fire Safety $J$ 1995; 24: 167-87.

[36] Beitelmal AH, Saad MA, Patel CD. The effect of inclination on the heat transfer between a flat surface and an impinging two-dimensional air jet. Int J Heat Fluid Flow 2000; 21 (2): 156-63.

[37] Delichatsios MA. Transition from momentum to buoyancy-controlled turbulent jet diffusion flames and flame height relationships. Combust Flame 1993; 92: 349-64.

[38] White JP, Link ED, Trouvé AC, Sunderland PB, Marshall AW, Sheffel JA, et al. Radiative emissions measurements from a buoyant, turbulent line flame under oxidizer-dilution quenching conditions. Fire Safety J 2015; 76: 74-84.

[39] Merci B, Beji T. Fluid mechanics aspects of fire and smoke dynamics in enclosures. CRC press LLC, Boca Raton, USA, 2016.

[40] Noto K, Teramoto K, Nakajima T. Spectra and critical Grashof numbers for turbulent transition in a 
thermal plume. J Thermophys Heat Trans 1999; 13: 82-90.

[41] Otsu N. A threshold selection method from gray-level histograms. IEEE Trans Syst Man Cyb 1979; 9: $62-6$.

[42] Portscht R. Studies on characteristic fluctuations of the flame radiation emitted by fires. Combust Sci Technol 1975; 10: 73-84.

[43] Lee YP, Delichatsios MA, Ohmiya Y, Wakatsuki K, Yanagisawa A, Goto D. Heat fluxes on opposite building wall by flames emerging from an enclosure. Proc Combust Inst 2009; 32: 2551-8.

[44] Zhang XC, Hu LH, Zhang XL, Yang LZ, Wang SF. Non-dimensional correlations on flame height and axial temperature profile of a buoyant turbulent line-source jet fire plume. J Fire Sci 2014; 32 (5): 406-16.

[45] Hu LH, Liu SX, Zhang XL. Flame heights of line-source buoyant turbulent non-premixed jets with air entrainment constraint by two parallel side walls. Fuel 2017; 200: 583-9.

[46] Karlsson B, Quintiere JG. Enclosure fire dynamics, CRC Press LLC, 2000.

[47] Hasemi Y, Nishihata M. Fuel shape effect on the deterministic properties of turbulent diffusion flames. Fire Safety Science- Proceedings of the Second International Symposium 1989, 275-84.

[48] Delichatsios MA. Critical conditions for upward flame spread and comparison with empirical flammability indices. Combust Sci Technol 1995; 106: 125-36.

[49] Heskestad G. On $\dot{Q}^{*}$ and the dynamics of turbulent diffusion flames. Fire Safety J 1998; 30: 215-27.

[50] Fire Dynamics Simulator User's Guide, NIST Special Publication 1019, National Institute of Standards and Technology, 2013, Gaithersburg, Maryland.

[51] Sun XP, Zhang XL, Hu LH, Kuwana K. Temperature evolution and transition inside fire compartment with an opening subject to external sideward wind. Proc Combust Inst 2019; 37 (3): 3869-77.

[52] Livkiss K, Husted BP, Beji T, Van Hees P. Numerical study of a fire-driven flow in a narrow cavity. 
Fire Safety J 2019; 108: Article 102834.

[53] Quintiere JG, Grove BS. A unified analysis for fire plumes. Symp (Int) Combust 1998; 27: 2757-66.

[54] Delichatsios MA. Air entrainment into buoyant jet flames and pool fires. Combust Flame 1987; 70: $33-46$.

[55] Khatami R, Stivers C, Joshi K, Levendis YA, Sarofim AF. Combustion behavior of single particles from three different coal ranks and from sugar cane bagasse in $\mathrm{O} 2 / \mathrm{N} 2$ and $\mathrm{O} 2 / \mathrm{CO} 2$ atmospheres. Combust Flame 2012; 159: 1253-71.

[56] Yuan LM, Cox G. An experimental study of some line fires. Fire Safety J 1996; 27: 123-39. 


\section{Appendix A. Literature flame height data by different methods}

Figures A.1(a) and A.1(b) compare the normalized mean flame heights of this work with literature data $[27,28,38,47,56]$ all belonging to the line-source flame correlation regime (i.e. flame heights depend on the $2 / 3$ power of the heat release rate).

For the free flame height in Fig. A.1(a), Yuan et al. [56] conducted an experimental study using two burners having dimensions $L \times W: 0.20 \mathrm{~m} \times 0.015 \mathrm{~m}$ and $0.50 \mathrm{~m} \times 0.015 \mathrm{~m}$, where the mean height of the visible flame tips were obtained from 3 minutes samples of video records. The correlation of their data [56] is plotted in Fig. A.1(a) employing the present coordinates:

$$
\frac{H_{f, \text { mean }}}{2(L+W)}=6.59 \dot{Q}_{f r e e}^{* 2 / 3}
$$

The data in [47] as shown in Fig. A.1(a) concerns flame heights in a line-source burner $(1 \mathrm{~m} \times 0.1 \mathrm{~m})$ where the reported values of flame height are the average of the height of flame-tips observed of the videotape for more than 3 minutes at the intervals of $1 \mathrm{~s}$. Their data have the following relation employing the coordinates of this work:

$$
\frac{H_{f, \text { mean }}}{2(L+W)}=7.02 \dot{Q}_{\text {free }}^{* 2 / 3}
$$

In a recent paper [38], a line-source burner $(0.50 \mathrm{~m} \times 0.05 \mathrm{~m})$ was used and the same method as in this work was used to obtain the flame height. Their correlation line (taking the radiative heat loss fraction to be 0.3 ) is expressed as shown in Fig. A.1(a):

$$
\frac{H_{f, \text { mean }}}{2(L+W)}=4.31 \dot{Q}_{\text {free }}^{* 2 / 3}
$$

From Fig. A.1(a) and Eqs. (A.1)-(A.3), we can see that the correlation based on the work in [38] which uses the same method as ours to get the flame height is close to this work in contrast to the correlations 
in $[47,56]$.

For the wall attached flame, the data from [28] shown in Fig. A.1(b) were deduced from video recordings frame by frame, by an average of 30 consecutive flame tip heights. The flame height is represented by

$$
\frac{H_{f, \text { mean }}}{2(L+2 W)}=5.49 \dot{Q}_{\text {wall }}^{* 2 / 3}
$$

which is similar to the correlation in our work.

The data from [27] in Fig. A1(b) is the average flame tip heights for 3 minutes at intervals of 0.5 seconds on the videotape, and a correlation, which has a larger coefficient, is found

$$
\frac{H_{f, \text { mean }}}{2(L+2 W)}=7.19 \dot{Q}_{\text {wall }}^{* 2 / 3}
$$

By comparing Eq. (A.2) and Eq. (A.5) obtained from the same authors [27, 46], we note that they are almost the same showing for free and wall attached flames, which represents maximum flame heights (flame tips).

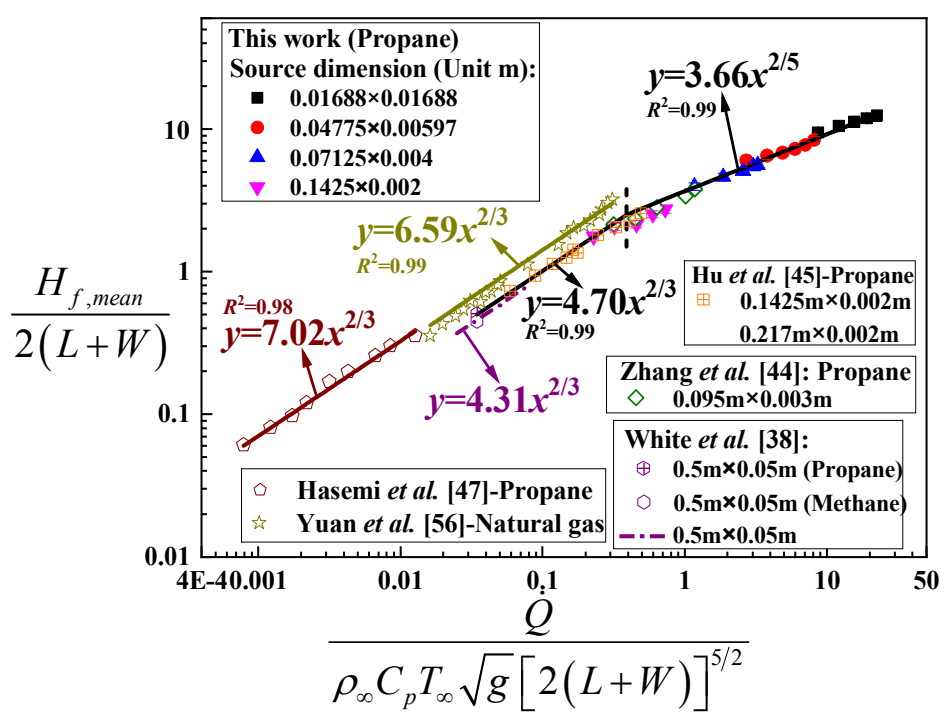

(a) free flame 


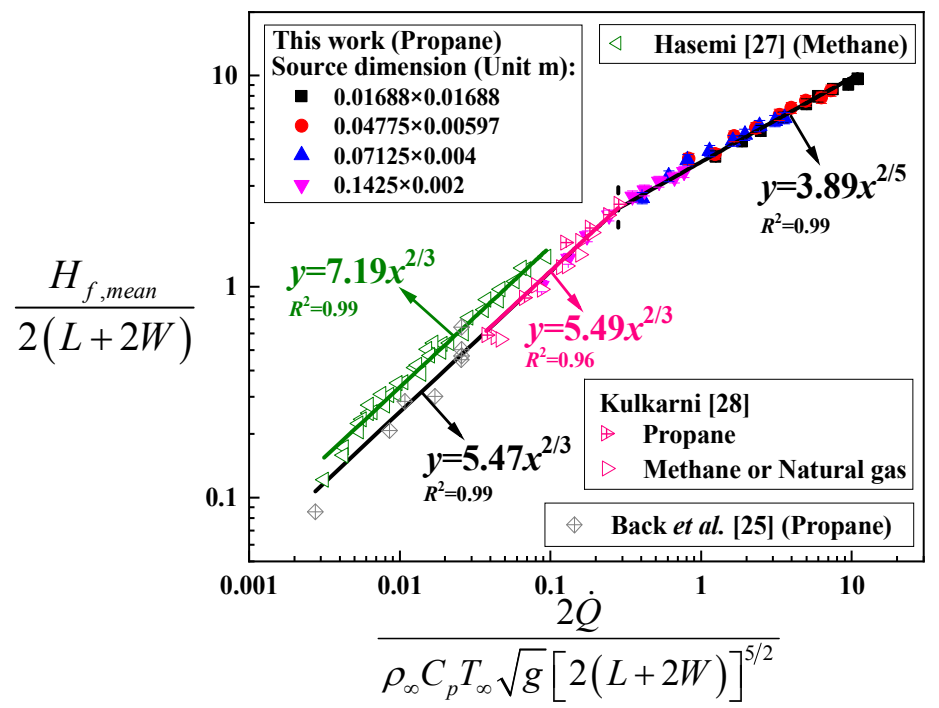

(b) wall attached flame

Fig. A.1 Normalized flame height for both free flames and wall attached flames and comparison with the data reported in the literatures $[27,28,38,47,56]$, showing the two-regimes behavior although the data obtained by different methods have some inherent difference. 


\section{$\underline{\text { Figure captions }}$}

Fig. 1: a) Increasing natural gas consumption of China in recent 10 years; b) A case of nature gas pipeline leakage fire accident near a building wall in the city [Cited from http://news.sina.com.cn] (consulted on 12/2018).

Fig. 2: (a) Experimental setup and typical flame intermittency contours for wall attached buoyancy driven turbulent flames (nozzle: $47.75 \mathrm{~mm} \times 5.97 \mathrm{~mm}$; heat release rate: $19.64 \mathrm{~kW}$ ); (b) Determination of flame morphologic parameters based on image processing.

Fig. 3: Variation of mean flame height (based on the 0.5 flame intermittency) with $H R R$ for both free flames and wall attached flames.

Fig. 4: Normalized mean flame height for wall attached flames and free flames based on Eq. (1) and Eq. (2) ("mirror" treatment), respectively, showing that the non-dimensional flame heights of both wall attached flames and free flames experience a two-dimensional to three-dimensional transition.

Fig. 5: CFD simulation setup and mesh sizes.

Fig. 6: FDS simulation results of temperature profiles and velocity vectors of both the free flame and the wall attached flame for the source of $47.75 \mathrm{~mm} \times 5.97 \mathrm{~mm}$ with heat release rate of $8.93 \mathrm{~kW}$.

Fig. 7: Flame height fluctuation range for free buoyancy driven flames and wall attached flames, showing that the flame height fluctuation of wall attached flame is smaller than that of free flame, and decreases with the increasing of the burner aspect ratio.

Fig. 8: The ratio of the mean flame height to the minimum flame height for free flames and wall attached flames which has the similar behavior with the flame height fluctuation range in Fig. 7.

Fig. 9: Ratio of maximum mean flame width to the mean flame height for both free flames and wall attached flames.

Fig. 10: Correlation of normalized flame width with non-dimensional heat release rate for both free flames and wall attached flames.

Fig. 11: Ratio of maximum mean flame thickness to the mean flame height for both free flames and wall attached flames. 
Fig. 12: Correlations of normalized flame thickness with non-dimensional heat release rate for both free flames and wall attached flames.

Fig. A.1: Normalized flame height for both free flames and wall attached flames and comparison with the data reported in the literatures $[27,28,38,47,56]$, showing the two-regimes behavior although the data obtained by different methods have some inherent difference. 


\section{Table captions}

Table. 1: Summary of experimental conditions of both wall attached flames and free flames. 